\title{
1 Consistent replacement of small- by large-ranged plant species across habitats
}

2

Ingmar R. Staude ${ }^{1,2}$, Henrique M. Pereira ${ }^{1,2,3}$, Gergana Daskalova, Markus Bernhardt-Römermann ${ }^{5}$, Martin Diekmann $^{6}$, Harald Pauli 7,8 , Hans Van Calster ${ }^{9}$, Mark Vellend ${ }^{10}$, Anne D Bjorkman ${ }^{11,12}$, Jörg Brunet ${ }^{13}$, Pieter De Frenne ${ }^{14}$, Radim Hédl ${ }^{15,16}$, Ute Jandt ${ }^{1,2}$, Jonathan Lenoir ${ }^{17}$, Isla H. Myers-Smith4, Kris Verheyen ${ }^{14}$, Sonja Wipf ${ }^{18,19}$, Monika Wulf ${ }^{20}$, Christopher Andrews ${ }^{21}$, Peter Barančok ${ }^{22}$, Elena Barni ${ }^{23}$, José-Luis Benito-Alonso ${ }^{24}$, Jonathan Bennie $^{25}$, Imre Berki ${ }^{26}$, Volker Blüml ${ }^{27}$, Markéta Chudomelová15 ${ }^{15}$ Guillaume Decocq ${ }^{17}$, Jan Dick ${ }^{21}$, Thomas Dirnböck $^{28}$, Tomasz Durak ${ }^{29}$, Ove Eriksson ${ }^{30}$, Brigitta Erschbamer ${ }^{31}$, Bente Jessen Graae ${ }^{32}$, Thilo Heinken ${ }^{33}$, Fride Høistad Schei ${ }^{34}$, Bogdan Jaroszewicz ${ }^{35}$, Martin Kopecký ${ }^{36,37}$, Thomas Kudernatsch ${ }^{38}$, Martin Macek ${ }^{36}$, Marek Malicki ${ }^{39,40}$, František Máliš ${ }^{41,42}$, Ottar Michelsen ${ }^{43}$, Tobias Naaf ${ }^{44}$, Thomas A. Nagel ${ }^{45}$, Adrian C. Newton ${ }^{46}$, Lena Nicklas ${ }^{31}$, Ludovica Oddi ${ }^{23}$, Adrienne Ortmann-Ajkai ${ }^{47}$, Andrej Palaj ${ }^{22}$, Alessandro Petraglia ${ }^{48}$, Petr Petřík ${ }^{49}$, Remigiusz Pielech ${ }^{50,51}$, Francesco Porro ${ }^{52}$, Mihai Pușcaș ${ }^{53,54}$, Kamila Reczyńska ${ }^{39}$, Christian Rixen ${ }^{18}$, Wolfgang Schmidt ${ }^{55}$, Tibor Standovár ${ }^{56}$, Klaus Steinbauer ${ }^{8}$, Krzysztof Świerkosz ${ }^{57}$, Balázs Teleki ${ }^{58,59}$, Jean-Paul Theurillat ${ }^{60,61}$, Pavel Dan Turtureanu ${ }^{53}$, Tudor-Mihai Ursu ${ }^{62}$, Thomas Vanneste ${ }^{14}$, Philippine Vergeer ${ }^{63}$, Ondřej Vild ${ }^{36}$, Luis Villar ${ }^{64}$, Pascal Vittoz ${ }^{65}$, Manuela Winkler ${ }^{7,66}$, Lander Baeten ${ }^{14}$

\section{German Centre for Integrative Biodiversity Research (iDiv) Halle-Jena Leipzig, Leipzig, Germany}

2. Institute of Biology, Martin Luther University Halle-Wittenberg, Halle (Saale), Germany

3. CIBIO (Research Centre in Biodiversity and Genetic Resources)-InBIO (Research Network in Biodiversity and Evolutionary Biology), Universidade do Porto, 4485-661 Vairão, Portugal

4. School of GeoSciences, University of Edinburgh, Edinburgh, Scotland, UK

5. Institute of Ecology and Evolution, Friedrich Schiller University Jena, Jena, Germany

6. Institut für Ökologie, Universität Bremen, Bremen, Germany

7. GLORIA Coordination, Institute for Interdisciplinary Mountain Research at the Austrian Academy of Sciences (ÖAW-IGF), Vienna, Austria

8. GLORIA Coordination, Department of Integrative Biology and Biodiversity Research at the University of Natural Resources and Life Sciences Vienna, Austria

9. Research Institute for Nature and Forest, Brussels, Belgium

10. Département de biologie, Université de Sherbrooke, Québec, Canada

11. Department of Biological and Environmental Sciences, University of Gothenburg, 40530 Gothenburg, Sweden

12. Gothenburg Global Biodiversity Centre, 40530 Gothenburg, Sweden

13. Southern Swedish Forest Research Centre, Swedish University of Agricultural Sciences, Box 49, 23053 Alnarp, Sweden

14. Forest \& Nature Lab, Ghent University, Gontrode, Belgium

15. Institute of Botany, Czech Academy of Sciences, Brno, Czech Republic

16. Department of Botany, Faculty of Science, Palacký University in Olomouc, Olomouc, Czech Republic

17. UR "Ecologie et Dynamique des Systèmes Anthropisés" (EDYSAN, UMR7058 CNRS), Université de Picardie Jules Verne, 1 rue des Louvels, F-80000 Amiens, France

18. WSL Institute for Snow and Avalanche Research SLF, Flüelastrasse 11, Davos, Switzerland

19. Swiss National Park, 7530 Zernez, Switzerland

20. Leibniz Centre for Agricultural Landscape Research (ZALF), Research Area 2, Müncheberg, Germany

21. UK Centre for Ecology and Hydrology, Bush Estate, Penicuik, Midlothian, EH26 OQB, UK

22. Institute of Landscape Ecology, Slovak Academy of Sciences, Štefánikova 3, 81499 Bratislava, Slovakia 
23. Department of Life Sciences and Systems Biology, University of Turin, Italy

24. GLORIA-Aragon Coordination, Jolube Consultor Botánico y Editor, Jaca, Huesca, Spain

25. Centre for Geography and Environmental Science, Exeter University, Penryn Campus, Penryn, Cornwall TR10 9FE, UK 26. Faculty of Forestry, University of Sopron, Sopron, Hungary 27. BMS-Umweltplanung, Osnabrück, Germany 28. Environment Agency Austria, Spittelauer Lände 5, 1090 Vienna, Austria 29. Laboratory of Plant Physiology and Ecology, University of Rzeszów, Rejtana 16c, PL-35-959 Rzeszów, Poland 30. Department of Ecology, Environment and Plant Sciences, Stockholm University, Sweden 31. Department of Botany, University of Innsbruck, Sternwartestr. 15, 6020 Innsbruck, Austria 32. Department of Biology, NTNU, Høgskoleringen 5, 7091 Trondheim, Norway

33. University of Potsdam, Institute of Biochemistry and Biology, Maulbeerallee 3, 14469 Potsdam, Germany 34. Norwegian Institute of Bioeconomy Research, Thormøhlensgate 55, 5006 Bergen, Norway. 35. Białowieża Geobotanical Station, Faculty of Biology, University of Warsaw, Sportowa 19, 17-230 Białowieża, Poland 36. Institute of Botany of the Czech Academy of Sciences, Zámek 1, CZ-252 43, Prühonice, Czech Republic 37. Faculty of Forestry and Wood Sciences, Czech University of Life Sciences Prague, Kamýcká 129, CZ-165 21, Praha 6 Suchdol, Czech Republic

38. Bavarian State Institute of Forestry Hans-Carl-von-Carlowitz-Platz 185354 Freising (Deutschland - Germany) 39. Department of Botany, Faculty of Biological Sciences, University of Wrocław, Kanonia 6/8, PL-50-328 Wrocław, Poland 40. Department of Pharmaceutical Biology and Biotechnology, Wroclaw Medical University, Poland 41. Faculty of Forestry, Technical University in Zvolen, Zvolen, Slovakia 42. National Forest Centre, Zvolen, Slovakia

43. Department of Industrial Economics and Technology Management, Norwegian University of Science and Technology (NTNU), 7491 Trondheim, Norway

44. Leibniz Centre for Agricultural Landscape Research (ZALF), Muencheberg, Germany

45. Department of forestry and renewable forest resources, Biotechnical Faculty, University of Ljubljana, Večna pot 83, Ljubljana 1000, Slovenia

46. Department of Life and Environmental Sciences, Bournemouth University, Poole, Dorset, UK BH21 $5 B B$

47. Institute of Biology, University of Pécs, Hungary

48. Department of Chemistry, Life Sciences and Environmental Sustainability, University of Parma, Parco Area delle Scienze 11/A, 43124, Parma, Italy

49. Czech Academy of Sciences, Institute of Botany, Zámek 1, CZ-25243 Průhonice

50. Department of Forest Biodiversity, University of Agriculture, al. 29 Listopada 46, 31-425 Kraków, Poland 51. Foundation for Biodiversity Research, ul. Terenowa 4c/6, 52-231 Wrocław, Poland 52. University of Pavia, Department of Earth and Environmental Sciences, via Ferrata 1, Pavia, 27100, Italy 53. A. Borza Botanical Garden, Babeș-Bolyai University Cluj-Napoca, Republicii 42, Romania 54. Center for Systematic Biology, Biodiversity and Bioresources - 3B, Faculty of Biology and Geology, Babeș-Bolyai University Cluj-Napoca, Republicii 42, Romania

55. Department of Silviculture and Forest Ecology of the Temperate Zones, University of Göttingen, Germany 56. Department of Plant Systematics, Ecology and Theoretical Biology, Institute of Biology, Loránd Eötvös University, Pázmány S. 1/C, H-1117 Budapest, Hungary

57. Museum of Natural History, University of Wrocław, Sienkiewicza 21, PL-50-335 Wroclaw. Poland 58. MTA-DE Lendület Functional and Restoration Ecology Research Group, H-4032 Debrecen Egyetem sqr. 1, Hungary 59. PTE KPVK Institute for Regional Development 7100 Szekszárd Rákóczi str. 1, Hungary 
60. Fondation J.-M.Aubert, Champex-Lac, Switzerland

1. Department of Botany and Plant Biology, University of Geneva, Chambésy, Switzerland

62. Institute of Biological Research Cluj-Napoca, branch of NIRDBS Bucharest, Romania.

63. Wageningen University, Department of Environmental Sciences, PO Box 47, 6700 AA, Wageningen, the Netherlands 64. Instituto Pirenaico de Ecología, IPE-CSIC. Avda. de la Victoria, 12. 22700 Jaca, Huesca, Spain 65. Institute of Earth Surface Dynamics, Faculty of Geosciences and Environment, University of Lausanne, 1015 Lausanne, Switzerland 66. GLORIA Coordination, Department of Integrative Biology and Biodiversity Research at the University of Natural Resources

Corresponding author: Ingmar R. Staude

Email: ingmar.staude@idiv.de

Author Contributions: IRS, HMP, GD and LB conceived the study, with input from the sREplot working group (MBR, MD, HP, MV, ADB, JB, PDF, RH, UJ, JL, IHM, KV, SW, M. Wulf). IRS performed the analyses, with input from HMP, GD, LB and HVC. IRS, HMP, GD and LB wrote the manuscript, with substantial input from MBR, ADB, MD, IHM, HP, MV, and contributions from JB, HVC, PDF, RH, UJ, JL, KV, SW, M. Wulf, CA, PB, EB, J. Benito-Alonso, J. Bennie, IB, VB, MC, GD, JD, T. Dirnböck, T. Durak, OE, BE, BJG, TH, FHS, BJ, MK, TK, M. Macek, M. Malicki, FM, OM, TN, TAN, ACN, LN, LO, AO, A. Palaj, A. Petraglia, PP, RP, FP, MP, KR, CR, WS, TS, KS, KŚ, BT, JT, PDT, TU, TV, P. Vergeer, P. Vittoz, OV, LV and M. Winkler. Authorship order was determined as follows: (1) core authors; (2) 


\section{Abstract}

The direction and magnitude of long-term changes in local plant species richness are highly variable among studies, while species turnover is ubiquitous. However, it is unknown whether the nature of species turnover is idiosyncratic or whether certain types of species are consistently gained or lost across different habitats. To address this question, we analyzed the trajectories of 1,827 vascular plant species over time intervals of up to 78 years at 141 sites in three habitats in Europe-mountain summits, forests, and lowland grasslands. Consistent across all habitats, we found that plant species with small geographic ranges tended to be replaced by species with large ranges, despite habitat-specific trends in species richness. Our results point to a predictable component of species turnover, likely explained by aspects of species' niches correlated with geographic range size. Species with larger ranges tend to be associated with nutrient-rich sites and we found community composition shifts towards more nutrientdemanding species in all three habitats. Global changes involving increased resource availability are thus likely to favor large-ranged, nutrient-demanding species, which are typically strong competitors. Declines of small-ranged species could reflect not only abiotic drivers of global change, but also biotic pressure from increased competition. Our study highlights the need to consider the traits of species such as the geographic range size when predicting how ecological communities will respond to global change.

\section{Significance Statement}

Vegetation resurveys at intervals of up to 78 years spanning mountain summits, forests and grasslands in Europe, reveal systematic temporal turnover of vascular plant species, despite variable trends in species richness. Large-ranged, nutrient-demanding species are consistently replacing species with small ranges, thus homogenizing vegetation between dominant habitats across Europe. Our crosscontinent comparison highlights that such gains of species might increase competition and contribute to directional species loss. Our findings inform predictions of plant community change and prioritization of species conservation during the Anthropocene.

\section{Main text}

\section{Introduction}

Long-term studies of changes in local plant species richness do not show systematic evidence of decline (1-3). However, local richness changes provide only a limited picture of the extent of ongoing biodiversity change, as they do not capture species turnover and changes in community composition over time (4). While human activities have accelerated species turnover beyond background rates (2, 3), it remains unclear whether the identities of "winner" and "loser" species represent the idiosyncratic local outcomes of drivers of change (e.g., disturbance or climate warming), or whether there are consistent patterns across systems (5). In order to gain a general understanding of why and how plant diversity is changing, we need to ask whether similar types of plant species are consistently lost and gained in communities in different habitats.

For plant species, studying temporal turnover in relation to their geographic range size can provide insights on why and how species diversity is changing. On the one hand, the geographic range size of plant species is a key synthetic measure of their ecological profile (6). Range size reflects the ability of species to disperse and colonize $(7,8)$, as well as their niche breadth $(9,10)$ and niche position $(11-$ 
13), thus capturing multiple factors relating to a species' vulnerability to global environmental changes. On the other hand, range size links temporal with spatial turnover of species, as communities that lose small-ranged while gaining widespread species become more similar over time (14). Therefore, understanding the link between range size and a species' trajectory over time will not only shed light on why certain species "win" or "lose", but also on the consequences of these shifts for the distinctiveness of plant communities, an important component of biodiversity.

Here, we analyze individual trajectories of 1,827 vascular plant species over time in relation to their range size at 141 study sites across three habitats in Europe - mountain summits, deciduous and coniferous forests, and lowland grasslands (Figure 1), using vegetation resurveys spanning intervals of 12 to 78 years. Temporal trends in local species richness and drivers of change are known to vary among these habitats, with climate warming increasing local species richness on summits $(15,16)$, eutrophication and changes in management reducing richness in grasslands $(17,18)$, and a combination of these drivers leading to both increases and decreases in richness in forests $(13,19-$ 21). We hypothesize that, regardless of the richness trend in a habitat, smaller-ranged species are consistently replaced by larger-ranged species, as environmental changes (such as increasing temperatures, land-use change and eutrophication) alter ecological selection processes in favor of widespread species; species that are expected to be more resilient, more nutrient-demanding and better dispersed $(13,22)$. Our study explores whether the temporal turnover of species of vascular plants is systematic, and whether it acts to homogenize vegetation between habitats.

\section{Results and Discussion}

We found that vascular plant species with larger ranges consistently emerged as winners and those with smaller ranges as losers over time across all three habitats, regardless of trends in species richness. While on mountain summits, species gains were clearly more prominent than species losses, there was substantial species loss in forests and grasslands (Figure 2a). Losses and gains, however, balanced out in forests, whereas in grasslands losses outweighed gains (Figure 2b). Thus, the average species richness increased on summits, showed no clear trend in forest and decreased in grasslands (Figure 2c and Fig. S1), in accordance with single-habitat studies from each of these habitats (summits: $(15,16)$, forests: $(13,19)$ and grasslands: $(17,18))$. Despite variable trends in richness, species turnover was systematic. We tested whether species with smaller ranges have been lost preferentially at a study site. Even after accounting for demographic effects (i.e., due to the likelihood that smallranged species are lost simply because of a smaller local population size; see Methods), range size was negatively associated with loss probability in all three habitats, although on summits the association was not statistically clear as the 66\% credible interval overlapped with zero (Figure 3a and Table S2). Effect estimates for forests and grasslands were robust to excluding rare species (with site- 
occupancies below $5 \%$ in the baseline survey) from the data (Table S2). We then asked whether changes in site-occupancy of persisting species were related to range size. In all three habitats, persisting species increasing in occupancy had larger ranges on average than species decreasing in occupancy (Fig. S3 and Table S3). This relationship persisted after accounting for species baseline occupancy (Figure 3b, see Methods). Finally, we compared range sizes of species gained to species lost. In all three habitats, species that were newly gained at a study site had, on average, larger ranges than species lost (Figure 3c, $d$ and Table S4). Together, these findings indicate commonalities between contrasting habitats with respect to the nature of biodiversity change based on species range size.

Across habitats, plant species with larger ranges gained ground. The success of large-ranged species could be due to previously limiting resources (e.g., nutrients) becoming more available as a result of global changes such as eutrophication and warming $(23,24)$. A greater availability of limiting resources allows less specialized species to colonize, where larger-ranged species may be more likely to colonize simply because they disperse from more sites. Larger-ranged species may also be more likely to persist because they naturally face a larger gradient in environmental conditions and may thus exhibit a greater niche breadth and phenotypic plasticity, making them more resilient to global changes $(10,22$, 25). Furthermore, global changes may even favor large-ranged species, as they tend to be species with resource-acquisitive strategies and might therefore benefit more from an increase in resources (12, 13, 22). We found support for this hypothesis in our data; species with larger ranges were associated with higher nutrient demands (Figure 4a) and community weighted means of species niche positions for nutrients indicated community shifts towards more nutrient-demanding species (Figure $4 b$, see Methods), in accordance with other studies in these habitats (summits: (26), forests: (19) and grasslands: (18)). These findings suggest that a higher prevalence of larger-ranged species, often also more resource-acquisitive species, is likely to exert increased biotic pressure on extant species.

In contrast to large-ranged species, small-ranged species tend to be adapted to lower nutrient availability (Figure 4) and thus are likely to grow more slowly (27), presenting a particular risk of competitive exclusion by faster growing species. The loss of small-ranged species could therefore be a result of the increase in less specialized, more competitive, larger-ranged species (i.e. biotic filtering). Furthermore, small-ranged species tend to have adaptations to the stresses specific to their habitat and therefore possibly a lower tolerance to new types of stress, such as stoichiometric imbalances in resource supply from eutrophication (28). Thus, the decline in small-ranged species could also be due to direct effects of environmental change (i.e. abiotic filtering). Importantly, we can largely exclude the potential explanation that the higher loss probability of small-ranged species is due only to stochastic, demographic effects (Table S2, see Methods). Also, if small-ranged species were simply more prone to demographic fluctuations and therefore had a more variable presence, we would expect comparable range sizes of species lost and gained, which we do not see in the data (Figure $3 c$ and d). Thus, the 
preferential loss of small-ranged species is likely due not only to demographic stochasticity, but also to aspects of species niche that confer a higher vulnerability to both abiotic and biotic pressures.

237

Despite the congruence across habitats of small-ranged species being replaced by large-ranged species, our results also indicate differences in the effect of range size on temporal species turnover between habitats. On summits, the effect of range size on species loss probability was weakest and not clearly different from zero (Figure 3a). Moreover, species gained on summits had larger ranges than both persisting and lost species, whereas in forests and grasslands the main distinction was that species lost had smaller ranges than both persisting and gained species (Figure $3 c$ and Table S4). In addition, on summits, species gains dominated and species losses were less important for driving turnover compared with forests and grasslands (Figure $2 \mathrm{a}$ and $\mathrm{b}$ ). These results suggest that the directional turnover on summits in relation to species range size could be mainly due to species differences in dispersal and colonization ability. On summits, warming may allow the colonization of species from lower elevations, which tend to have larger ranges (Fig. S5), while extant species may persist and escape changes in abiotic and biotic filters due to a high variation of micro-habitats (29, 30) and a still sparse or less tall-growing vegetation $(31,32)$. In forests and grasslands, the vegetation is typically denser than on summits. Environmental changes, such as eutrophication or declines in traditional land use, are thus likely to lead, in addition to abiotic changes, to higher biotic pressure (33, 34). We hypothesize that a greater relevance of biotic filtering in forests and grasslands could contribute to the more directional loss of small-ranged species in these habitats (Figure 3). Although any cross-habitat comparison is limited due to inherent differences between habitats, we can rule out that differences in the relationship of range size and loss probability simply arise from evident differences in sampling methods among study sites. The number of plots, plot size, site area and time span between surveys did not change the effect of range size on the probability of loss (see Methods and Table S5). Our results thus support the potential role of indirect, biotic effects of global change in understanding the preferential loss of small-ranged species.

Altogether, our results suggest that temporal species turnover has a predictable component based on species range size. Regardless of whether site-level trends show increases or decreases in species richness, larger-ranged species replaced smaller-ranged species. This has at least two implications. First, as sites gain species that are already widespread and lose small-ranged species, cumulatively this may lead to shifts from characteristic, often rare vegetation types to more widespread vegetation types - a form of biotic homogenization (14). Indeed, we found that an average pair of study sites became more similar in species composition and, moreover, that the total species pools of the three habitats became more similar over time (Fig. S6a and b). Second, small-ranged species may be doubly at risk of extinction (35), both because of purely geographical reasons, as they by definition occupy 
fewer sites, and because they can also be more vulnerable to being lost within each site, as we have shown here. While the patterns found in our study suggest that the loss of small-ranged species within sites is partially explained by species niches, it remains a future challenge to disentangle how much of this loss is driven by indirect effects due to altered competitive interactions (i.e. biotic filtering) versus direct effects due to environmental changes (i.e. abiotic filtering) in different habitats. Our study demonstrates that even in seminatural habitats, biodiversity is systematically changing and that this change can be predicted by the geographic range size of species. Thus, our results inform predictions of how plant communities will respond to accelerating global change and the prioritization of conservation efforts towards the species that are more likely to be lost. Insights on the relative importance of biotic versus abiotic filtering will be essential when prioritizing measures to reverse the declines of the most vulnerable species in the Anthropocene.

\section{Materials and Methods}

Databases. We synthesized data from three databases, each of which is a collation of vegetation resurveys in a specific habitat in Europe. Mountain summits are represented by 52 sites from the Global Observation Research Initiative in Alpine environments (GLORIA, gloria.ac.at, (36)), deciduous and coniferous forests understories by 68 sites from the forestREplot database (forestreplot.ugent.be, (37)) and lowland grasslands by 21 sites from the GRACE database (18) (Figure 1 and Table S1). At each site, plant communities were surveyed across multiple permanent or quasi-permanent plots in either natural vegetation (summits) or semi-natural vegetation (forests and grasslands) at two points in time (baseline and resurvey, further details available in $(18,36,37)$ ). The median time spans between surveys were 14, 42 and 34 years for summits, forests and grasslands, respectively (Fig. S7a). In forest and grassland surveys, the median number of plots per site was 43 and 36 , and the median size of plots was $400 \mathrm{~m}^{2}$ and $25 \mathrm{~m}^{2}$, respectively (Fig. S8a and b). Summits were always resurveyed in eight spatial sections that together covered the entire area from the highest summit point to the contour line $10 \mathrm{~m}$ in elevation below this point in a pie slice shape. The median summit area was 0.25 ha. In forests and grasslands, the median study area was 1,700 ha and 1,000 ha, respectively (Figure S8b).

Species data. Taxonomy. We accounted for within-and among-study variation in taxonomy by determining the accepted species name for each species using the Global Biodiversity Information Facility's (GBIF) backbone taxonomy (gbif.org). Harmonization thus ensured no double-counting of species owing to synonymy. We included only vascular plants identified to the species level. In total, 
our data comprises 1,827 accepted vascular plant species (see Data Table 1 at figshare.com/s/b37f6167b13ad5da9e9c).

Range size. We estimated species range sizes as area of occupancy (AOO) (6) using all point occurrence records of the species in GBIF (gbif.org, May 2020; (38)). After excluding incomplete, impossible and unlikely coordinates (e.g., country centroids) (39), there were c. 131 million geographically referenced records available for the species in our database. Records were aggregated to a hexagonal grid (ISEA3H) at a spatial grain of $10.7 \mathrm{~km}^{2}(40)$, where the number of cells that a species occupies on this grid represents its AOO estimate (see Data Table 1 for species AOO estimates and GBIF urls). The species with the largest AOO in all three habitats were Achillea millefolium and Trifolium repens (both with ca. $1.1 \times 10^{6} \mathrm{~km}^{2}$ ), the species with the smallest AOO were the highly endemic Draba dolomitica (c. $11 \mathrm{~km}^{2}$ ) on summits, Galium abaujense (c. $21 \mathrm{~km}^{2}$; endemic to the Carpathians) in forests, and Pentanema germanicum (c. $503 \mathrm{~km}^{2}$; critically endangered in Germany and Austria (41)) in grasslands (Fig. S9). For plant species in Europe, range sizes calculated from GBIF correlate strongly with expert drawn range maps but are available for many more species (13). However, it is important to note that $\mathrm{AOO}$ ranges differ from expert maps, which measure species extent of occurrence (EOO), in that they do not include areas that are unoccupied by species. Thus, species with disjunct distributions, e.g., orchid species that occur throughout Europe but only in very fragmented, well-conserved habitat, can have a very small AOO but a large EOO. AOO is therefore a markedly better representation of species population sizes and differences related to habitat use and species niche than is EOO, and provides a general measure of species vulnerabilities to stochastic and directional threatening processes (6).

Occupancy. Measures of plot-level species abundance varied across studies (e.g., frequencies, percentage cover, and categorical cover-abundance scales) and were often not available if only species presence/absence was recorded. In order to estimate species abundance in a consistent way, we estimated species occupancy at the spatial scale of a study. We therefore divided the number of plots (grasslands, forests) or sections (summits) a species occupied at a given study site by the total number of plots/sections in that study. This was done separately for the baseline survey and the resurvey. Occupancy has been shown to correlate strongly and positively with abundance at local to regional scales $(42,43)$.

Trajectory. We evaluated species trajectories (i.e. lost, gained or persisting) at the spatial scale of a study site. Lost species were present (in at least one plot/section) during the baseline survey and absent (from all plots/sections) during the resurvey. Gained species were absent during the baseline survey and present during the resurvey. Persisting species were present during both the baseline survey and resurvey. Resurveys, even of permanent plots, always miss some species, generating 
pseudo-gains and losses that can be inflated for rare species $(44,45)$. We account for this bias by adjusting for species baseline abundances, which is strongly correlated with any such bias (46), as explained below.

Analysis. The brms package (47) in R was used for all statistical analyses. R code for all analyses and data visualization is available on figshare at https://figshare.com/s/b37f6167b13ad5da9e9c.

Species gains and losses. Using species trajectories we quantified the number of lost and gained species on the spatial scale of a study site (Extended Data Table 2). The highest losses (126 species) occurred in Hungarian forest-steppe landscapes, the highest gains (102 species) occurred in acidic/mesic oak woods in the Czech Republic. We assessed changes in species richness (i.e., the change in the total number of species per study site) by calculating the difference, $d$, between species richness in the resurvey $\left(t_{2}\right)$ and species richness in the baseline survey $\left(t_{1}\right)$. Although species richness at a given time period will be affected by sampling effort, $d$ is not because it is a relative change in species richness with sampling effort being the same for both time periods (baseline surveys vs. resurveys). For each habitat, we modelled $d$ using a Gaussian distribution to compute the posterior distribution of the expected value of $d$ (Fig. S1).

Probability of loss. We estimated the effect of species range size on the probability that a species being present at the baseline survey is lost from a study site by the time of the resurvey. The effect of range size can be confounded by species baseline occupancy if small-ranged species also tend to have a lower abundance at a study site. Species with small population sizes are more likely to be lost owing to 1) stochastic demographic processes and 2) an observer error, where rare species are more likely to be overlooked in resurveys. Therefore, we tested first for a positive range size - site occupancy relationship in our data (see Methods below). Range size and occupancy were not related on summits and weakly positively related in forests and grasslands (Fig. S2). To estimate the effect of range size that is not due to demographic effects, we statistically controlled for variation in species baseline occupancies by including it as a covariate in our model (13). Furthermore, species with small ranges may be disproportionately vulnerable at low abundances. This could be the case if range size covaries with specific traits, such as, for example, height, where small plants would be expected to be more vulnerable than tall plants at low site occupancy. To account for this possible further confounding effect, we also include an interaction effect between range size and occupancy in our model. Finally, the effect of species occupancy on species loss probability is likely to vary with the number of plots per study site. For example, a species with $10 \%$ occupancy in a study of 10 plots, is more likely to be lost than a species with $10 \%$ occupancy in a study of 100 plots. We therefore allow the effect of occupancy to vary by study site. 
Our model thus predicts a Bernoulli indicator variable that a given species was lost or persisted $\left(e_{i}\right)$ with two fixed effects ( $\beta_{r}$ for range size $\left(r_{i}\right)$ and $\beta_{f}$ for occupancy $\left(f_{i}\right)$, where both $r_{i}$ and $f_{i}$ were log10-transformed and scaled within habitats to have a mean of zero and a standard deviation of one) and an interaction effect between the two fixed effects $\left(\beta_{f r}\right)$. We allowed the intercept and the effect of occupancy to vary by study site ( $\alpha_{s t u d y[i]}$ and $\beta_{f, s t u d y[i]}$, respectively). Also, we included species as an additional crossed varying effect $\left(\gamma_{\text {species }[i]}\right)$, since many species occur in more than one study site. We ran this model for each habitat (see Table S2 for model R syntax, sample settings and convergence diagnostics). The resulting model in mathematical form is:

$$
\begin{aligned}
e_{i} & \sim \operatorname{Binomial}\left(1, p_{i}\right) \\
\operatorname{logit}\left(p_{i}\right) & =\alpha_{\text {study }[i]}+\gamma_{\text {species }[i]} \\
& +\beta_{f, s t u d y[i]} * f_{i}+\beta_{r} * r_{i}+\beta_{f r} * f_{i} * r_{i}
\end{aligned}
$$

As a further means to test whether demographic effects confound estimates of $\beta_{r}$, we ran the same model but excluded rare species (with site occupancies below 5\%) from our data (Table S3). Since we only had data on the species that were newly gained at a study site but not on all those that tried to colonize, we were not able to directly calculate probabilities of gain in relation to range size.

Occupancy trends of persisting species. Here we only evaluate species that have persisted over time, since species lost and gained necessarily decrease and increase in occupancy, respectively. We first tested whether persisting species that increased in occupancy at a study site have on average larger range sizes than persisting species that decreased in occupancy at a study site. We therefore predicted range size (log10-transformed) with the categorical variable "decrease/increase" $\left(\beta_{d i[i]}\right)$ including a group-level effect for study site $\left(\alpha_{s t u d y[i]}\right)$ :

$$
\begin{aligned}
r_{i} & \sim \operatorname{Normal}\left(\mu_{i}, \sigma\right) \\
\mu_{i} & =\alpha_{s t u d y[i]}+\beta_{d i[i]}
\end{aligned}
$$

397

387 Since changes in occupancy may depend on species baseline occupancy (e.g., species with a higher 388 baseline occupancy could be more likely to increase in occupancy due to a higher propagule pressure), 389 we also estimated the effect of species range size on the probability that a persisting species increases in occupancy, controlling for variation in species baseline occupancies. For this logistic model, we recoded the difference in occupancy at the resurvey and the baseline survey $(d)$ into a binary variable with $d>0$ being " 1 ", $d \leq 0$ being " 0 " $\left(h_{i}\right)$ and predicted $h_{i}$ with range size, including baseline occupancy as a covariate. Since baseline occupancy ranges from 0 to 1 , species with an occupancy of 1 cannot increase in occupancy. These species were therefore excluded from the model. The model in math form is: 


$$
\begin{aligned}
h_{i} & \sim \operatorname{Binomial}\left(1, p_{i}\right) \\
\operatorname{logit}\left(p_{i}\right) & =\alpha_{\text {study }[i]}+\gamma_{\text {species }[i]} \\
& +\beta_{f, s t u d y[i]} * f_{i}+\beta_{r} * r_{i}
\end{aligned}
$$

, where parameters are defined as in the model for species loss probability. However, we did not include the interaction effect between occupancy and range size $\left(\beta_{f r}\right)$ in this model, as a potentially greater vulnerability of small-ranged species at low occupancy is likely to not be very relevant to explain increases in occupancy (see Table S3 for model R syntax, sample settings and convergence diagnostics).

Difference in range sizes between trajectories. We calculated species mean range size for each trajectory to test whether species with larger ranges are gained preferentially. We therefore predicted range size (log10-transformed) with species trajectory $\left(\beta_{\operatorname{traj}[i]}\right)$, allowing the intercept to vary by study site $\left(\alpha_{s t u d y[i]}\right)$. We ran this model for each habitat:

$$
\begin{aligned}
r_{i} & \sim \operatorname{Normal}\left(\mu_{i}, \sigma\right) \\
\mu_{i} & =\alpha_{s t u d y[i]}+\beta_{\text {traj }[i]}
\end{aligned}
$$

In order to test whether range sizes of species gained differ from those being lost, we calculated the posterior difference in mean range size between gained and lost species in each habitat. Since the posterior difference between gained and lost species is in the log10-scale, this gives a ratio of range size of species gained/lost after back-transformed to the original scale (see Table S4 for model R syntax, sample settings and convergence diagnostics).

Range size and nutrient demand. We used Ellenberg's indicator values for nutrient ( $N$-number) to approximate species niche position for nutrients $(27,48,49)$. These values describe each species' niche position on a scale from 1 to 9 (adapted to unproductive, nutrient-poor soils) to 9 (adapted to fertile soils). We obtained N-numbers from sci.muni.cz/botany/juice/ELLENB.TXT and harmonized the taxonomy with our data. If an accepted species had more than one $\mathrm{N}$-number (either due to synonyms or subspecies, e.g., Melampyrum pratense ssp. paludosum has an N-number of 1, while Melampyrum pratense has an $\mathrm{N}$-number of 2), we calculated the average. 1,297 species of the 1,827 species in our data also had N-numbers (71\%). For the species in each habitat, we calculated Pearson's correlation coefficient between range size ( $\log 10$-transformed and scaled) and $\mathrm{N}$-number (scaled).

Community weighted mean of species nitrogen niche position. We tested whether communities shift towards species with higher nutrient demands over time by quantifying the community weighted mean N-number (CWM-N) at the time of the baseline survey and resurvey. CWM-N was calculated for each study site and survey period as: $\sum N_{i} * f_{i} / \sum f_{i}$ where $N_{i}$ and $f_{i}$ is the N-number and siteoccupancy of the $i^{\text {th }}$ species, respectively. We quantified the difference between resurvey and baseline 
survey CMW-N, by predicting CWM-N $\left(c_{i}\right)$ with survey period $\left(\beta_{\text {survey }[i]}\right)$, including study site as a group-level effect $\left(\alpha_{s t u d y[i]}\right)$ to indicate pairs of observations:

$$
\begin{aligned}
c_{i} & \sim \operatorname{Normal}\left(\mu_{i}, \sigma\right) \\
\mu_{i} & =\alpha_{s t u d y[i]}+\beta_{\text {survey }[i]}
\end{aligned}
$$

To gain insight into how much of the change in CWM-N is due to changes in species occupancy or species composition, we also calculated community unweighted means by simply averaging $\mathrm{N}$ numbers across species at a study site for both the baseline survey and resurvey, and tested for changes over time using the same model as above. The comparison of weighted and unweighted means showed that in forests and grasslands, the clear shift towards more nutrient-demanding species was largely due to changes in species composition, while on summits the much weaker shift was due to changes in species occupancy (Fig. S4).

\section{Supplementary analysis. Range size-site occupancy relationship. In each habitat, we predicted species} range size with species baseline occupancy at a study site (both variables were log10-transformed and scaled within habitats to have a mean of zero and a standard deviation of one), allowing the intercept and slope to vary by study site:

$$
\begin{aligned}
r_{i} & \sim \operatorname{Normal}\left(\mu_{i}, \sigma\right) \\
\mu_{i} & =\alpha_{\text {study }[i]}+\beta_{f, \text { study }[i]} * f_{i}
\end{aligned}
$$

Relationship between mean range size and elevation. We tested whether montane species from lower elevations have larger ranges than alpine ones. Therefore, we regressed mean range size $\left(m_{i}\right.$, averaged across species occurring at a summit site at the baseline survey) against summit elevation $\left(l_{i}\right)$ :

$$
\begin{aligned}
m_{i} & \sim \operatorname{Normal}\left(\mu_{i}, \sigma\right) \\
\mu_{i} & =\alpha+\beta_{l} * l_{i}
\end{aligned}
$$

Effects of site-characteristics on the effect of range size. While the above model for species loss probability provides estimates for range size-effects within habitats, different sampling methods between habitats make it difficult to compare effect estimates across habitats. Summits are inherently limited in size and were surveyed in always eight sections, while forest and grasslands areas were sampled with differing number of plots of different sizes across differently large study areas (Fig. S7 and 58). Moreover, time intervals between surveys varied among habitats, with the shortest intersurvey periods on summits (Table S1). To better compare effect estimates across habitats, we 
tested whether the effect of range size, $\beta_{r}$, changed with plot number, plot size, site area (log10transformed) and survey interval $\left(n_{i}, s_{i}, a_{i}\right.$, and $t_{i}$, respectively) We tested this in forests, where we had most study sites and sampling varied the most, by including interaction effects between range size and sampling characteristics (there was no strong collinearity between sampling characteristics (Fig. S10)):

$$
\begin{aligned}
e_{i} & \sim \operatorname{Binomial}\left(1, p_{i}\right) \\
\operatorname{logit}\left(p_{i}\right) & =\alpha_{\text {study }[i]}+\gamma_{\text {species }[i]} \\
& +\beta_{f, \text { study }[i]} * f_{i}+\beta_{r} * r_{i}+\beta_{f r} * f_{i} * r_{i} \\
& +\beta_{n r} * n_{i} * r_{i}+\beta_{s r} * s_{i} * r_{i}+\beta_{a r} * a_{i} * r_{i}+\beta_{t r} * t_{i} * r_{i}
\end{aligned}
$$

Changes in beta-diversity. We tested whether an average pair of communities becomes more similar

$$
\begin{aligned}
& b_{i} \sim \operatorname{Normal}\left(\mu_{i}, \sigma\right) \\
& \mu_{i}=\alpha+\beta_{\text {survey }[i]}
\end{aligned}
$$

Finally, we also quantified the multiple site Sørensen dissimilarity index (50) between the grassland,

forest and summit species pool for both survey periods.

$\mathrm{R}$ code for all analyses and data visualization, and complete species list with species range sizes and GBIF urls (Data Table 1) are available on figshare at https://figshare.com/s/b37f6167b13ad5da9e9c. Species composition data for grasslands is available from published literature compiled in (18); for forest and alpine summits these data are available upon request from forestreplot.ugent.be and gloria.ac.at, respectively.

This paper is an outcome of the sREplot working group supported by sDiv, the Synthesis Centre of the German Centre for Integrative Biodiversity Research (iDiv) Halle-Jena-Leipzig (DFG FZT 118). J. Benito-Alonso and LV were supported by the Dirección General de Cambio Climático del Gobierno de Aragón; the Ordesa y Monte Perdido National Park, and the Servicio de Medio Ambiente de Soria de la Junta de Castilla y León. JD and CEH/UKCEH staff were supported by the Natural Environment Research Council award number NE/R016429/1 as part of the UK-SCAPE programme delivering National Capability and access to the site facilitated by site owners Scottish Natural Heritage, Scotland's nature agency. T. Dirnböck was funded through the EU Horizon2020 INFRAIA project eLTER-PLUS (871128). B.E. received funding from Wissenschaftsförderung der Südtiroler Landesregierung, and Tiroler Wissenschaftsfonds. MC, MK, M. Macek, OV, PP and RH were supported by the Czech Academy of Sciences (project RVO 67985939). FM was supported by grant no. APVV-19-0319. TU was supported by the Ministry of Research and Innovation through Projects for Excellence Financing in RDI: Contract no. 22 PFE/2018 and PN2019-2022/19270201 - Ctr. 25N BIODIVERS 3-BIOSERV. P. Vergeer received funding of the Dutch Research Council by an Aspasia Grant. PDF received funding from the European Research Council (ERC) under the European Union's Horizon 2020 research and innovation programme (ERC Starting Grant FORMICA 757833). M. Winkler, BE, HP, JT, KS, LN, and P. Vittoz received funding from the Austrian Academy of 
Sciences for the project "MEDIALPS" in the frame of the Earth System Sciences Program. JT and P. Vittoz were supported by the the Swiss Federal Office of Education and Science and the Swiss Federal Office for the Environment. SW and CR were funded by the research commission of the Swiss National Park and the Giacomi foundation. GND was supported by a Carnegie-Caledonian PhD Scholarship and a NERC E3 Doctoral Training Partnership grant (NE/L002558/1). A. Palaj and PB were supported by the Scientific Grant Agency VEGA (project no. 2/0132/18). We thank the site co-ordinators R. Kanka, J. Kollár, U. Mora di Cella, M. Petey, G. Rossi and M. Tomaselli and numerous helpers for data originating from the GLORIA network.

\section{References cited}

1. M. Vellend, et al., Global meta-analysis reveals no net change in local-scale plant biodiversity over time. Proc. Natl. Acad. Sci. 110, 19456-19459 (2013).

2. M. Dornelas, et al., Assemblage time series reveal biodiversity change but not systematic loss. Science (80-. ). 344, 296-299 (2014).

3. S. A. Blowes, et al., The geography of biodiversity change in marine and terrestrial assemblages. Science (80-. ). 366, 339-345 (2019).

4. H. Hillebrand, et al., Biodiversity change is uncoupled from species richness trends: Consequences for conservation and monitoring. J. Appl. Ecol. 55, 169-184 (2018).

5. M. Dornelas, et al., A balance of winners and losers in the Anthropocene. Ecol. Lett. 22, 847854 (2019).

6. K. J. Gaston, R. A. Fuller, The sizes of species' geographic ranges. J. Appl. Ecol. 46, 1-9 (2009).

7. F. M. Schurr, et al., Colonization and persistence ability explain the extent to which plant species fill their potential range. Glob. Ecol. Biogeogr. 16, 449-459 (2007).

8. B. R. Murray, P. H. Thrall, A. M. Gill, A. B. Nicotra, How plant life-history and ecological traits relate to species rarity and commonness at varying spatial scales. Austral Ecol. 27, 291-310 (2002).

9. S. Kambach, et al., Of niches and distributions: range size increases with niche breadth both globally and regionally but regional estimates poorly relate to global estimates. Ecography (Cop.). 42, 467-477 (2019).

11. A. Pannek, J. Ewald, M. Diekmann, Resource-based determinants of range sizes of forest vascular plants in G ermany. Glob. Ecol. Biogeogr. 22, 1019-1028 (2013). 
range trade-off hypothesis. Ecol. Evol. 7, 11204-11212 (2017).

526

527

528

529

530

531

532

533

534

535

536

537

538

539

540

541

542

543

544

545

546

547

548

549

550

551

552

553

554

13. I. R. Staude, et al., Replacements of small- by large-ranged species scale up to diversity loss in Europe's temperate forest biome. Nat. Ecol. Evol. 4, 802-808 (2020).

14. M. L. McKinney, J. L. Lockwood, Biotic homogenization: a few winners replacing many losers in the next mass extinction. Trends Ecol. Evol. 14, 450-453 (1999).

15. H. Pauli, et al., Recent plant diversity changes on Europe's mountain summits. Science (80-. ). 336, 353-355 (2012).

16. M. J. Steinbauer, et al., Accelerated increase in plant species richness on mountain summits is linked to warming. Nature 556, 231 (2018).

17. K. Wesche, B. Krause, H. Culmsee, C. Leuschner, Fifty years of change in Central European grassland vegetation: Large losses in species richness and animal-pollinated plants. Biol. Conserv. 150, 76-85 (2012).

18. M. Diekmann, et al., Patterns of long-term vegetation change vary between different types of semi-natural grasslands in Western and Central Europe. J. Veg. Sci. 30, 187-202 (2019).

19. M. Bernhardt-Römermann, et al., Drivers of temporal changes in temperate forest plant diversity vary across spatial scales. Glob. Chang. Biol. 21, 3726-3737 (2015).

20. P. De Frenne, et al., Microclimate moderates plant responses to macroclimate warming. Proc. Natl. Acad. Sci. 110, 18561-18565 (2013).

21. G. N. Daskalova, et al., Landscape-scale forest loss as a catalyst of population and biodiversity change. Science (80-. ). 368, 1341-1347 (2020).

22. A. Estrada, et al., Species' intrinsic traits inform their range limitations and vulnerability under environmental change. Glob. Ecol. Biogeogr. 24, 849-858 (2015).

23. A. Salazar, K. Rousk, I. S. Jónsdóttir, J.-P. Bellenger, Ó. S. Andrésson, Faster nitrogen cycling and more fungal and root biomass in cold ecosystems under experimental warming: a metaanalysis. Ecology 101, e02938 (2020).

24. R. Bobbink, et al., Global assessment of nitrogen deposition effects on terrestrial plant diversity: a synthesis. Ecol. Appl. 20, 30-59 (2010).

25. O. Razgour, et al., Considering adaptive genetic variation in climate change vulnerability assessment reduces species range loss projections. Proc. Natl. Acad. Sci. 116, 10418-10423 (2019). 
26. S. B. Rumpf, et al., Range dynamics of mountain plants decrease with elevation. Proc. Natl. Acad. Sci. 115, 1848-1853 (2018).

27. M. Bartelheimer, P. Poschlod, Functional characterizations of E llenberg indicator values--a review on ecophysiological determinants. Funct. Ecol. 30, 506-516 (2016).

28. D. Kleijn, R. M. Bekker, R. Bobbink, M. C. C. De Graaf, J. G. M. Roelofs, In search for key biogeochemical factors affecting plant species persistence in heathland and acidic grasslands: a comparison of common and rare species. J. Appl. Ecol. 45, 680-687 (2008).

29. D. Scherrer, C. Körner, Topographically controlled thermal-habitat differentiation buffers alpine plant diversity against climate warming. J. Biogeogr. 38, 406-416 (2011).

30. B. J. Graae, et al., Stay or go--how topographic complexity influences alpine plant population and community responses to climate change. Perspect. Plant Ecol. Evol. Syst. 30, 41-50 (2018).

31. R. M. Callaway, et al., Positive interactions among alpine plants increase with stress. Nature 417,844 (2002).

32. W. D. Billings, H. A. Mooney, The ecology of arctic and alpine plants. Biol. Rev. 43, 481-529 (1968).

33. Y. Hautier, P. A. Niklaus, A. Hector, Competition for light causes plant biodiversity loss after eutrophication. Science (80-. ). 324, 636-638 (2009).

34. S. Meyer, K. Wesche, B. Krause, C. Leuschner, Dramatic losses of specialist arable plants in C entral G ermany since the 1950s/60s--a cross-regional analysis. Divers. Distrib. 19, 1175-1187 (2013).

35. S. L. Pimm, et al., The biodiversity of species and their rates of extinction, distribution, and protection. Science (80-. ). 344, 1246752 (2014).

36. H. Pauli, et al., The GLORIA field manual--standard Multi-Summit approach, supplementary methods and extra approaches (2015).

37. K. Verheyen, et al., Combining biodiversity resurveys across regions to advance global change research. Bioscience 67, 73-83 (2016).

38. GBIF.org (28 May 2020), GBIF Occurrence Download. $h$ ttps://doi.org/10.15468/dl.cxdh9m.

39. S. Chamberlain, scrubr: Clean Biological Occurrence Records. R Packag. version 0.3.2 (2020).

40. R. Barnes, K. Sahr, G. Evenden, A. Johnson, F. Warmerdam, dggridR: discrete global grids for R. $R$ Packag. version 0.112 (2017). 
41. M. A. Fischer, K. Oswald, W. Wagner, Exkursionsflora für Österreich, Liechtenstein und Südtirol. 3., verb. Aufl (2008).

42. D. H. Wright, Correlations between incidence and abundance are expected by chance. J. Biogeogr., 463-466 (1991).

43. K. J. Gaston, et al., Abundance--occupancy relationships. J. Appl. Ecol. 37, 39-59 (2000).

44. A. Futschik, et al., Disentangling observer error and climate change effects in long-term monitoring of alpine plant species composition and cover. J. Veg. Sci. 31, 14-25 (2020).

45. K. Verheyen, et al., Observer and relocation errors matter in resurveys of historical vegetation plots. J. Veg. Sci. 29, 812-823 (2018).

46. M. Kopecký, M. Macek, Vegetation resurvey is robust to plot location uncertainty. Divers. Distrib. 21, 322-330 (2015).

47. P.-C. Bürkner, brms: An R package for Bayesian multilevel models using Stan. J. Stat. Softw. 80, $1-28$ (2017).

48. H. Ellenberg, C. Leuschner, Vegetation Mitteleuropas mit den Alpen: in ökologischer, dynamischer und historischer sicht (Utb, 2010).

49. M. Diekmann, Species indicator values as an important tool in applied plant ecology--a review. Basic Appl. Ecol. 4, 493-506 (2003).

50. A. Baselga, C. D. L. Orme, betapart: an R package for the study of beta diversity. Methods Ecol. Evol. 3, 808-812 (2012). 


\section{Figures}
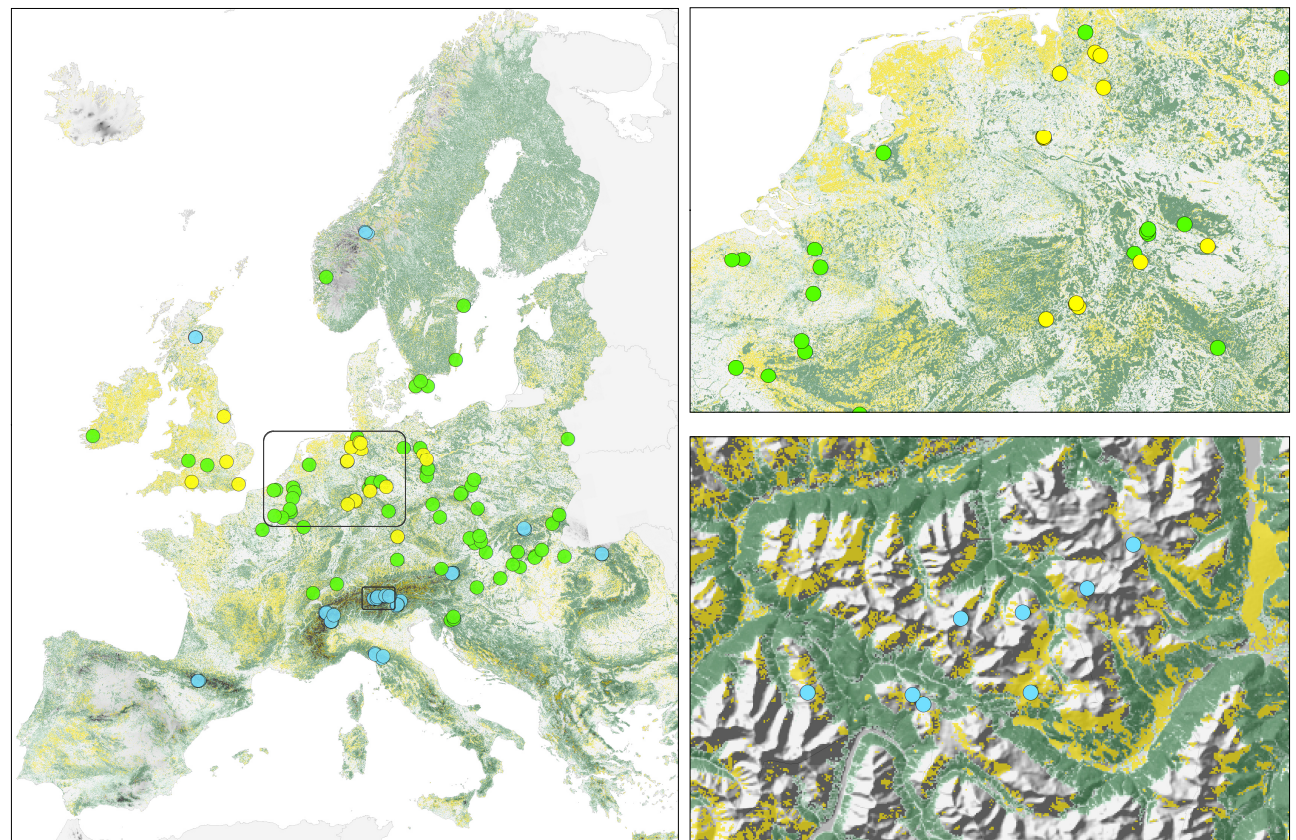

$\begin{array}{lcl}\text { Study site } \bigcirc \text { Mountain summit } \bigcirc \text { Deciduous and coniferous forest } \bigcirc \text { Lowland grassland } \\ \text { Land cover } & \text { Forest }\end{array}$

Figure 1. Our analysis spans 141 resurvey study sites. Resurveys are from three habitats in Europe: mountain summits $=52$ sites (blue), deciduous and coniferous forests $=68$ sites (green), and lowland grasslands $=21$ sites (yellow). CORINE forest cover (green) and grassland cover (yellow) in Europe are displayed along with elevation (dark shades). Insets show details for forests and grasslands (top), and summits (bottom). 

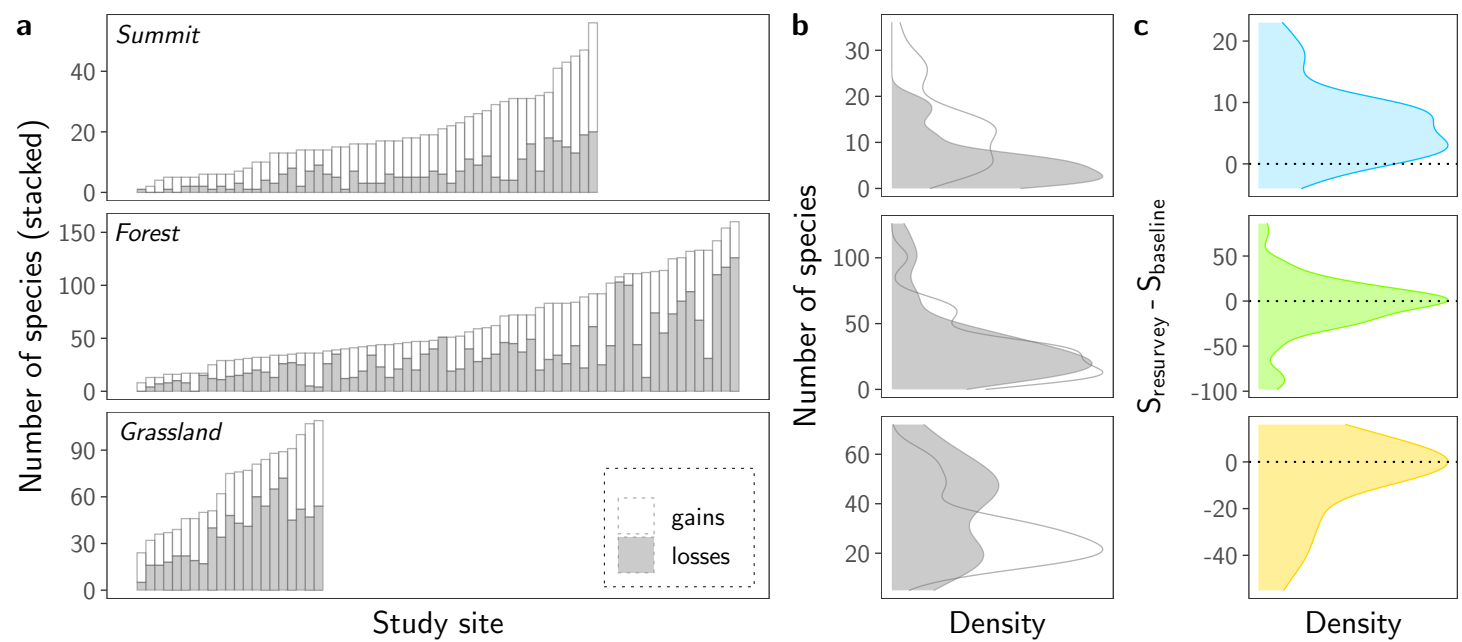

Figure 2. Species losses and gains vary across habitats. a, Species gains (white) and losses (grey) at each study site (numbers stacked, each bar represents a study site). b, Relative frequency (density) of the number of species lost and gained across sites. c, Density across study sites of the difference in species richness (S) between the baseline survey and resurvey. Dotted horizontal line represents zero change in S. Colours (blue, green, yellow) refer to habitats as in Figure 1. Posterior distribution of the mean difference in $S$ is shown in Supplementary Figure 1. 


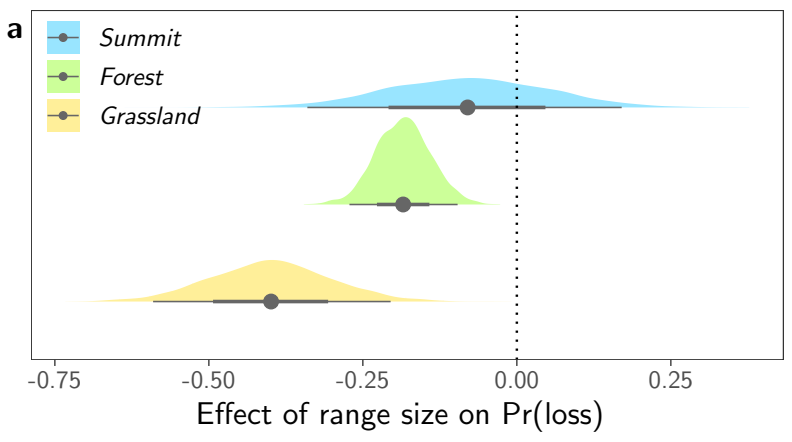

C

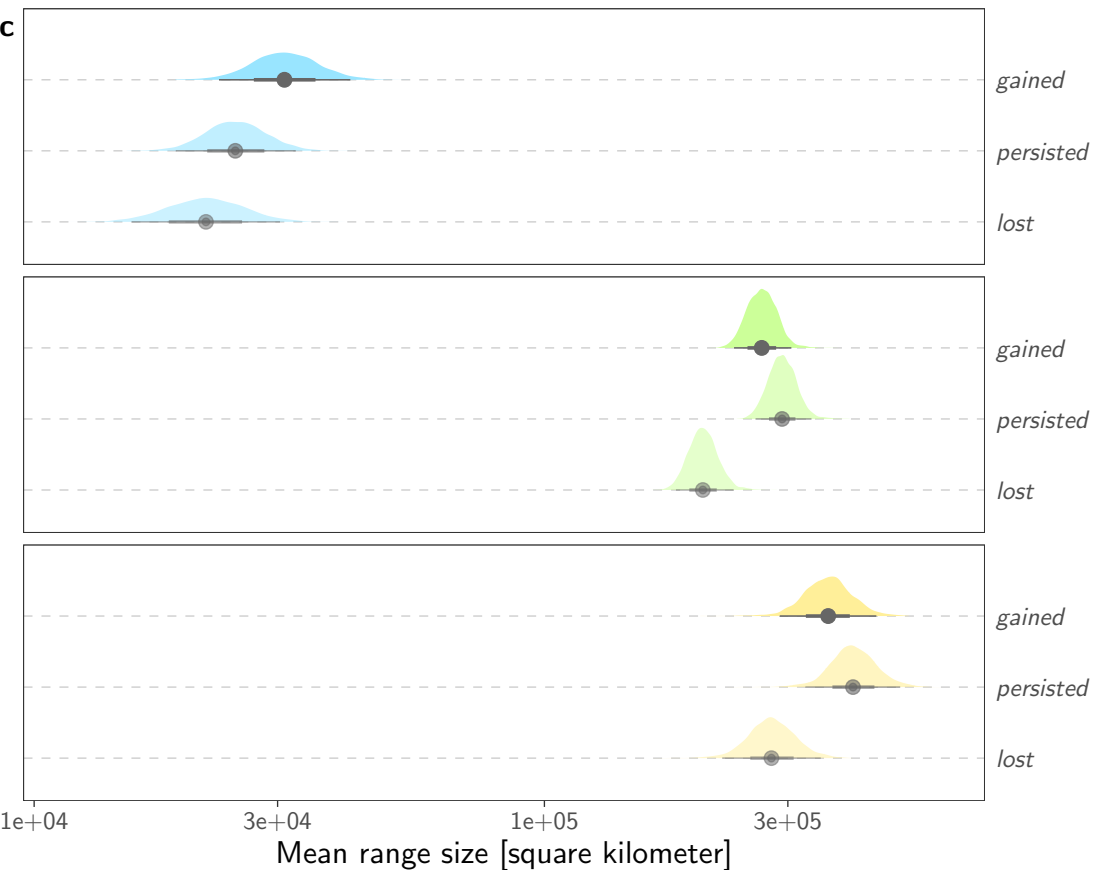

b

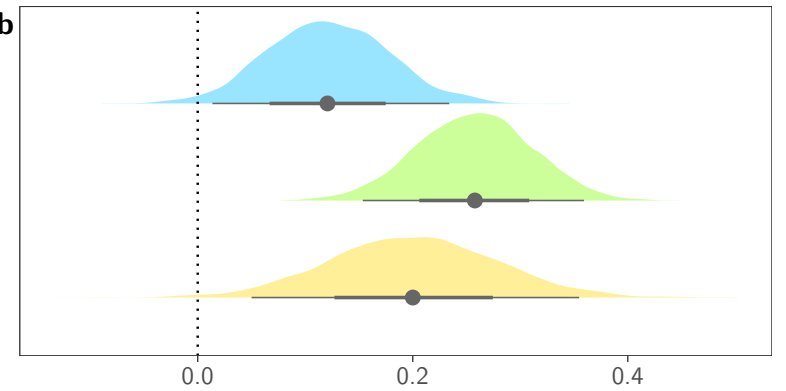

Effect of range size on $\operatorname{Pr}$ (increase)

Figure 3. Consistent replacement of small- by large-ranged species across habitats. Posterior distribution of the effect of range size on $\mathbf{a}$, the probability $(\mathrm{Pr})$ of a species being lost at a study site and $\mathbf{b}$, the probability (Pr) of a persisting species increasing in occupancy at a study site, after having accounted for demographic effects (see Methods). c, Posterior distribution of the mean range size of gained, persisting, and lost species. d, Comparison between the mean range sizes of species gained and lost, derived from the posterior distributions in c (persisting vs gained/lost comparison in Supplementary Table 4). Point and lines in a - $\mathbf{d}$ are the median and its $66 \%$ and $95 \%$ credible interval. Dotted vertical line in $\mathbf{d}$ represents no difference in mean range size. In a and b, range size was log10-transformed and scaled to have a mean of zero and a standard deviation of one, effect estimates (x-axis) are in the logit scale. Model summaries and sample sizes for panels a-d are in Supplementary Table 2-4. 

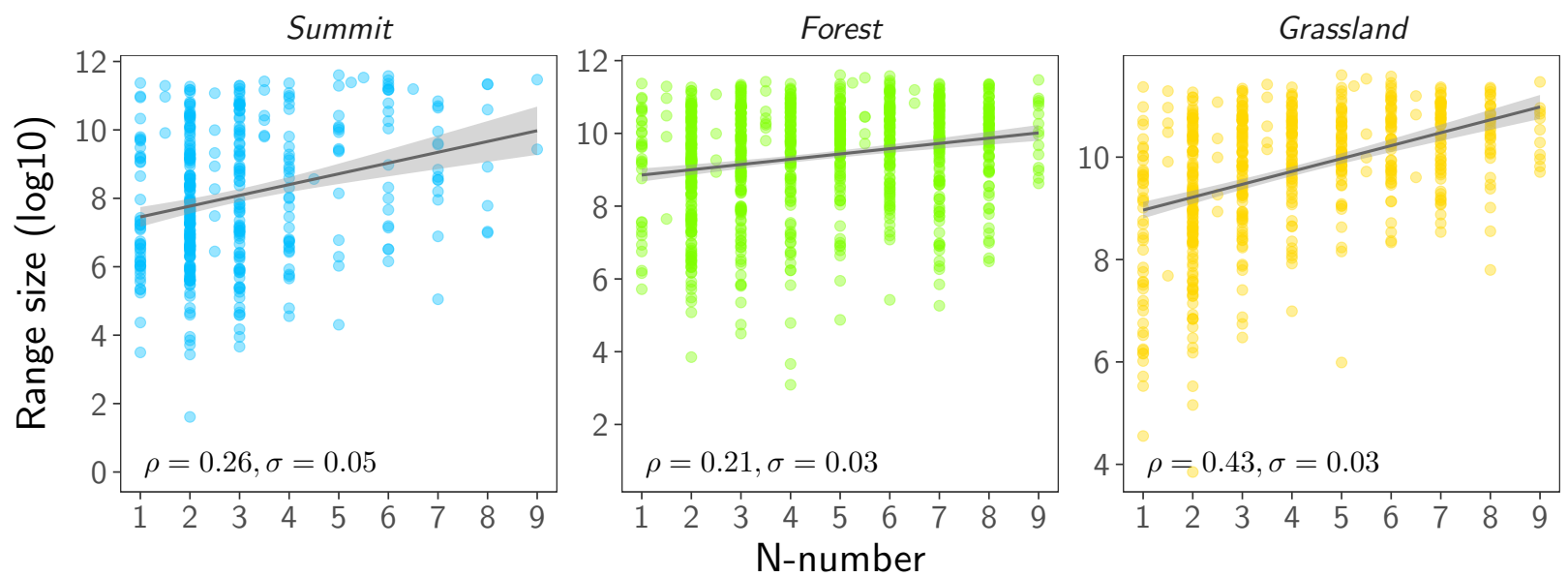

b Summit
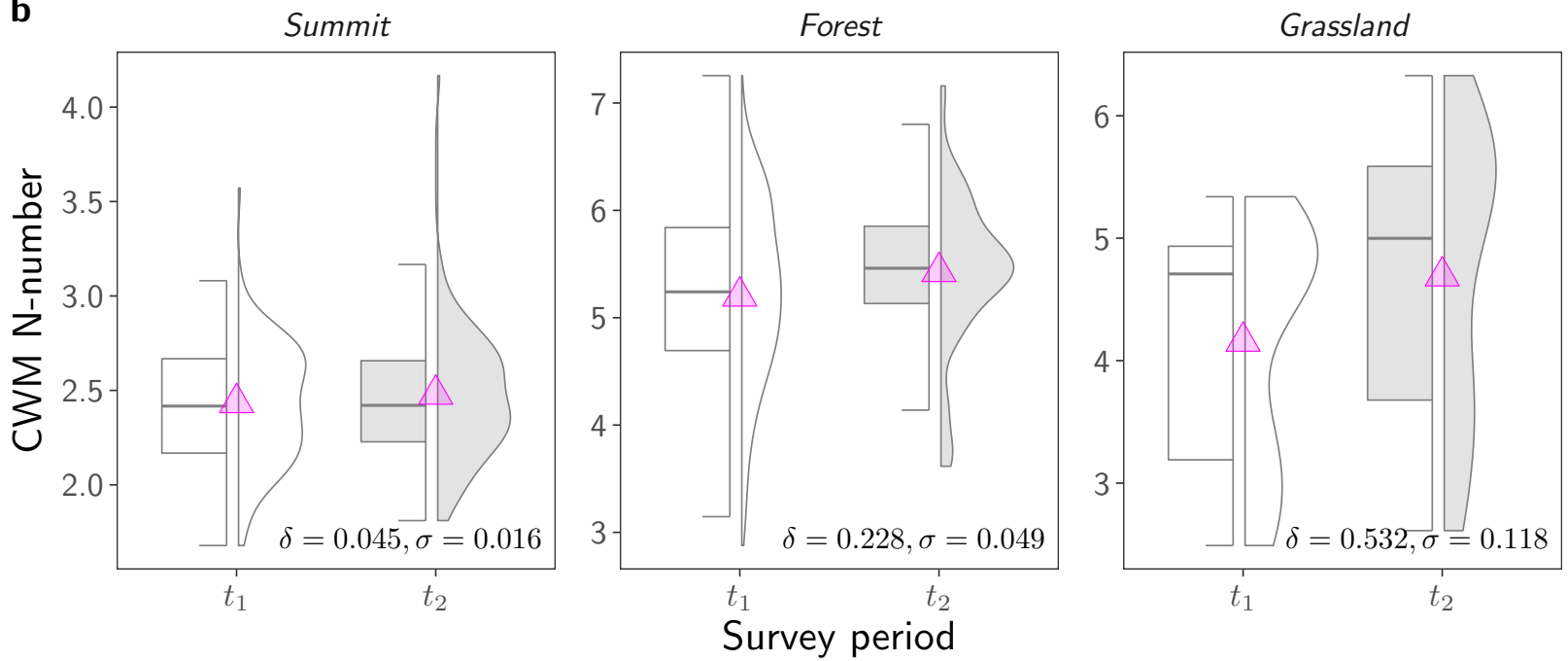

Figure 4. Species with larger ranges tend to have higher nutrient demands and communities shift towards species with higher nutrient demands over time. a, Relationship between species range size and Ellenberg indicator values for nutrients ( $\mathrm{N}$-numbers) across species in each habitat. Line and transparent ribbon represent the mean regression line and $95 \%$ credible interval, $\rho$ is the estimated correlation coefficient, $\sigma$ is the standard deviation of $\rho$. $\mathbf{b}$, Boxplot and density plot of the community weighted mean (CWM) niche position for nutrients ( $\mathrm{N}$-number) at the baseline survey $\left(t_{1}\right)$ and resurvey $\left(t_{2}\right)$. CWM is weighted by species occupancies at the study site. Triangles represent mean values. $\delta$ is the mean (pairwise) difference, $\sigma$ is the standard deviation of $\delta$. 


\section{Supplementary Materials for}

\section{Consistent replacement of small- by large-ranged plant species across habitats}

Ingmar R. Staude*, Henrique M. Pereira, Gergana Daskalova, Markus Bernhardt-Römermann, Martin Diekmann, Harald Pauli, Hans Van Calster, Mark Vellend, Anne D Bjorkman, Jörg Brunet, Pieter De Frenne, Radim Hédl, Ute Jandt, Jonathan Lenoir, Isla H. Myers-Smith, Kris Verheyen, Sonja Wipf, Monika Wulf, Christopher Andrews, Peter Barančok, Elena Barni, José-Luis Benito-Alonso, Jonathan Bennie, Imre Berki, Volker Blüml, Markéta Chudomelová, Guillaume Decocq, Jan Dick, Thomas Dirnböck, Tomasz Durak, Ove Eriksson, Brigitta Erschbamer, Bente Jessen Graae, Thilo Heinken, Fride Høistad Schei, Bogdan Jaroszewicz, Martin Kopecký, Thomas Kudernatsch, Martin Macek, Marek Malicki, František Máliš, Ottar Michelsen, Tobias Naaf, Thomas A. Nagel, Adrian C. Newton, Lena Nicklas, Ludovica Oddi, Adrienne Ortmann-Ajkai, Andrej Palaj, Alessandro Petraglia, Petr Petř́k, Remigiusz Pielech, Francesco Porro, Mihai Puscas, Kamila Reczyńska, Christian Rixen, Wolfgang Schmidt, Tibor Standovár, Klaus Steinbauer, Krzysztof Świerkosz, Balázs Teleki, Jean-Paul Theurillat, Pavel Dan Turtureanu, Tudor-Mihai Ursu, Thomas Vanneste, Philippine Vergeer, Ondřej Vild, Luis Villar, Pascal Vittoz, Manuela Winkler, Lander Baeten

*Corresponding author. Email: ingmar.staude@idiv.de

\section{Supplementary Figures}

1. Fig. S1. Temporal trends in species richness vary across habitats.

2. Fig. S2. Relationship between species range size and baseline site-occupancy.

3. Fig. S3. Persisting species increasing in occupancy have larger ranges than species decreasing.

4. Fig. S4. Temporal change of the mean $\mathrm{N}$-number.

5. Fig. S5. Species from lower elevations tend to have larger range sizes.

6. Fig. S6. Loss of beta-diversity over time.

7. Fig. S7. Histogram of time spans between surveys and site area.

8. Fig. S8. Histogram of plot numbers and sizes.

9. Fig. S9. Range size frequency distribution.

10. Fig. S10. Correlations between sampling characters of study sites in forests.

\section{Supplementary Tables}

1. Table S1. Study sites.

2. Table S2. Model summary: probability of a species to be lost.

3. Table S3. Model summary: occupancy trends of persisting species.

4. Table S4. Model summary: mean range sizes of gained, lost and persisting species.

5. Table S4. Model summary: interaction effects between sampling methods and range size. 


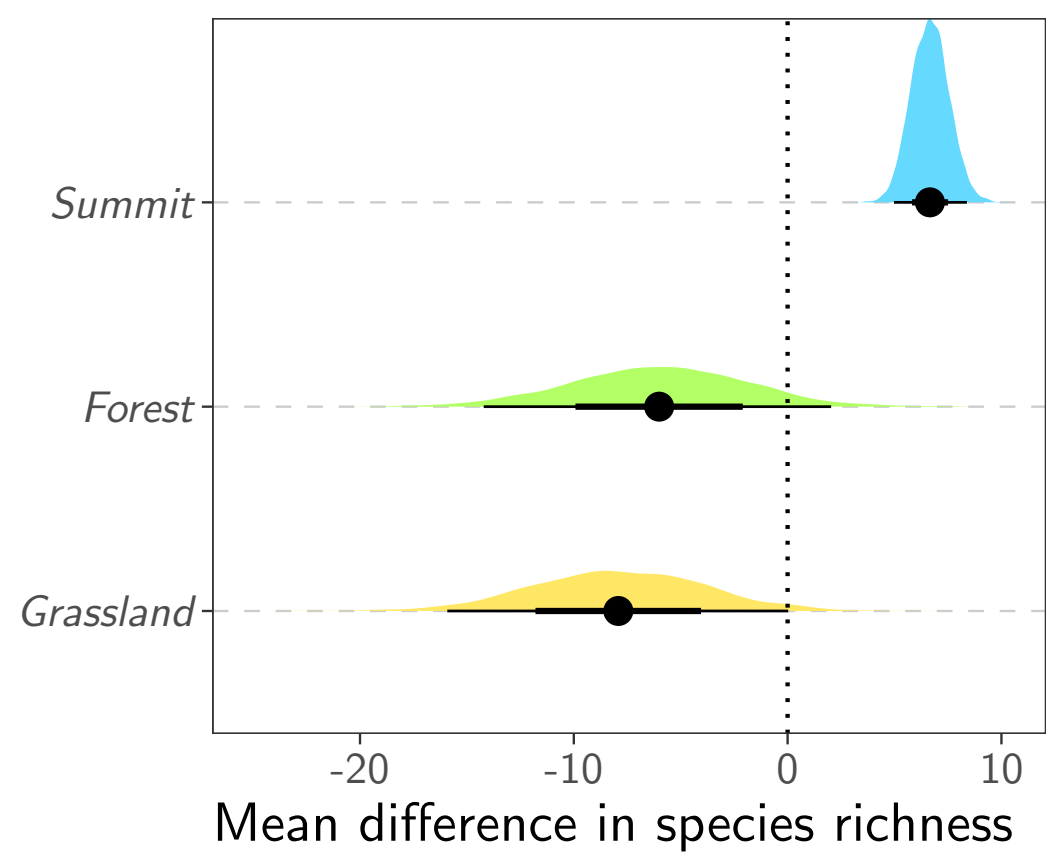

Fig. S1. Temporal trends in species richness vary across habitats. Posterior distribution of the mean difference in species richness at the study-site level between the resurvey and baseline survey. Points represent medians, lines represent the $66 \%$ and $95 \%$ confidence interval. The mean richness change and its standard deviation is for summits: $\delta=6.66, \sigma=0.88$; forests: $\delta=-6.04, \sigma=4.15$; and grasslands: $\delta=-7.90$, $\sigma=3.98$. Dotted vertical line represents zero change in richness. 


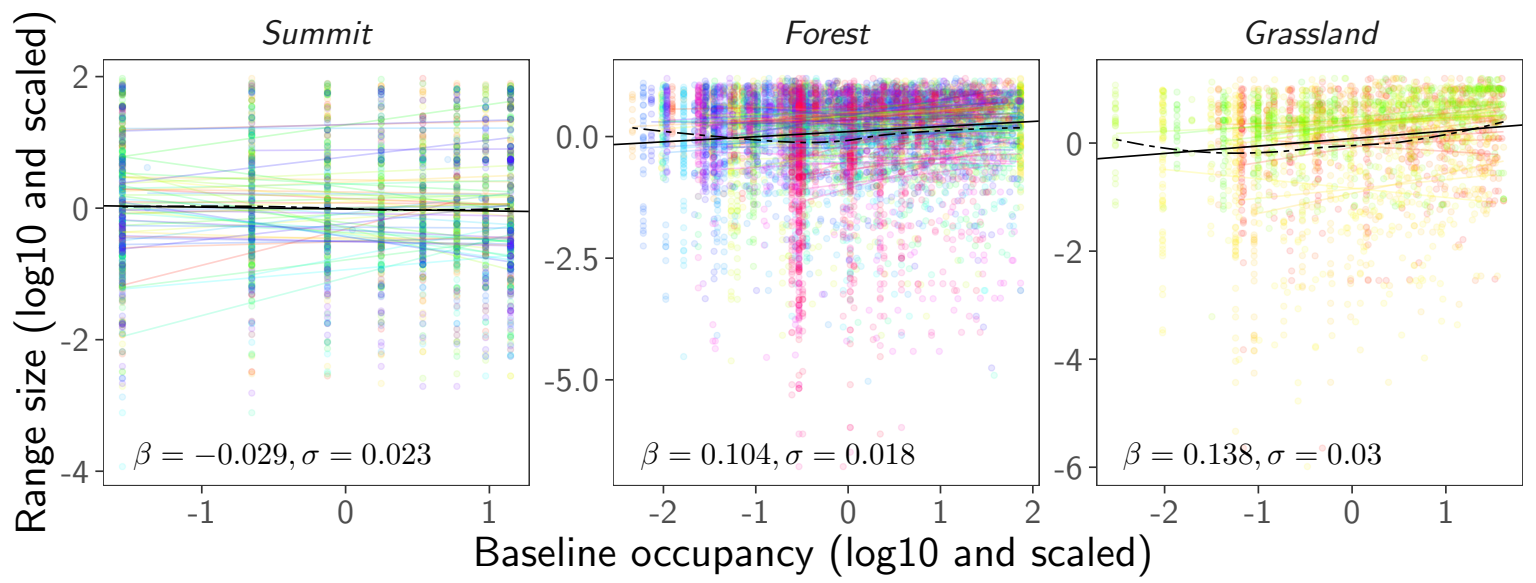

Fig. S2. Relationship between species range size and baseline site-occupancy accounting for the structure of our data. Colors present study sites, transparent dots present species, transparent lines represent the relationship between range size and site occupancy within a single study site, black straight line is the mean regression line across study sites resulting from a linear varying effect model with regression coefficients (slope and intercept) allowed to vary by study site, black dashed line is the mean regression line from a general additive model without varying effects. $\beta$ is the slope and $\sigma$ is the standard deviation of $\beta$ from the linear varying effect model. 

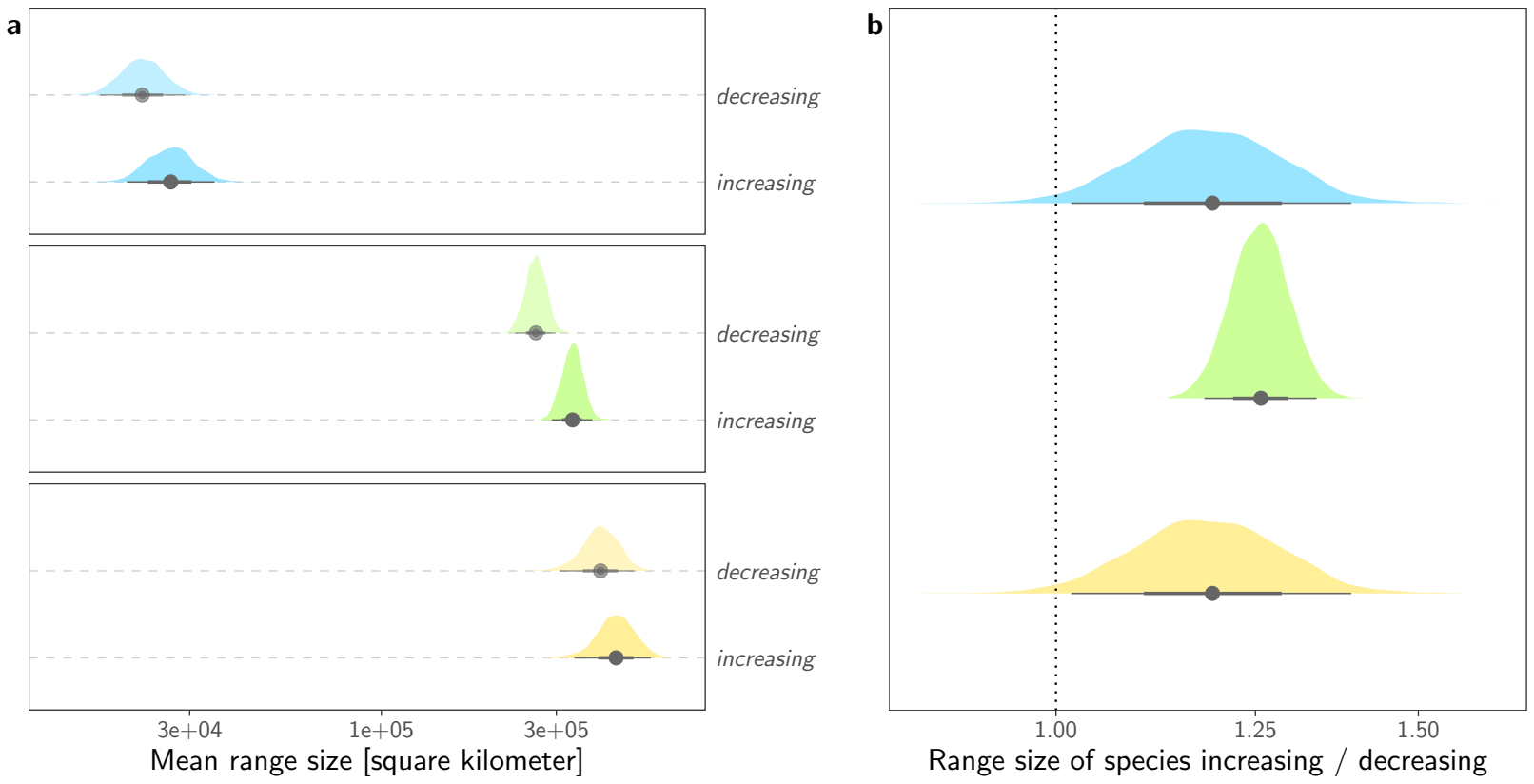

Fig. S3. Persisting species increasing in occupancy have larger ranges on average than species decreasing. a, Posterior distribution of the mean range size of species increasing and decreasing in occupancy at the study site over time. b, Comparison between the mean range sizes of species increasing and decreasing, derived from the posterior distributions in a. Colors refer to habitats as in Figure 1 (blue $=$ summit, green $=$ forest, yellow $=$ grassland). Point and lines are the median and its $66 \%$ and $95 \%$ credible interval. Dotted vertical line in $\mathbf{b}$ represents no difference in mean range size. See also Supplementary Table 3. 

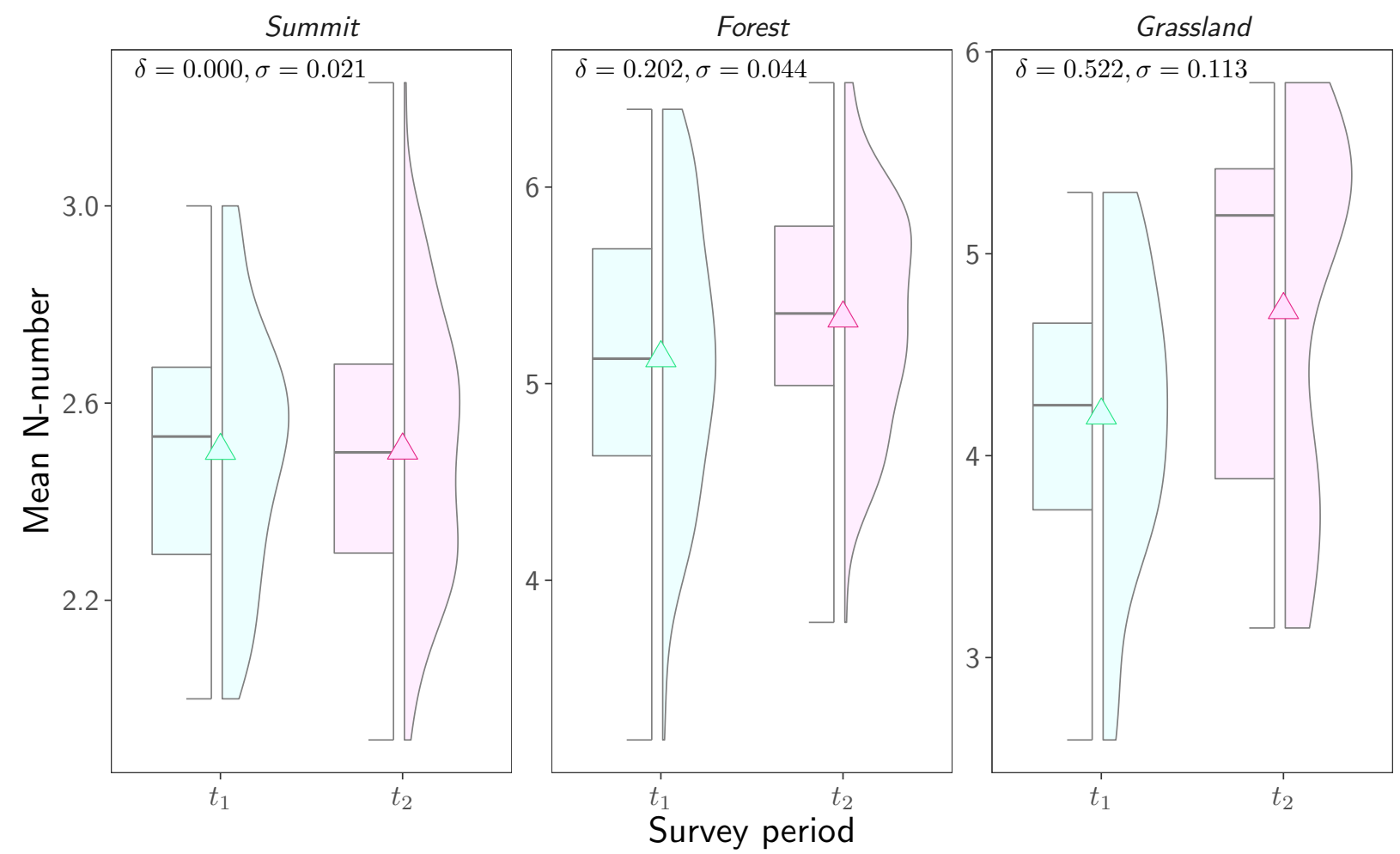

Fig. S4. Temporal change of the mean $\mathbf{N}$-number. Boxplot and density plot of the unweighted mean $\mathrm{N}$ number across species at the baseline survey $\left(t_{1}\right)$ and resurvey $\left(t_{2}\right)$. The comparison of weighted and unweighted means (Figure 4 vs Fig. S4) shows that in forests and grasslands, the shift towards more nutrient-demanding species is largely due to changes in species composition, while on summits the shift is due to changes in species occupancy. $\delta$ is the mean (pairwise) difference, $\sigma$ is the standard deviation of $\delta$. 


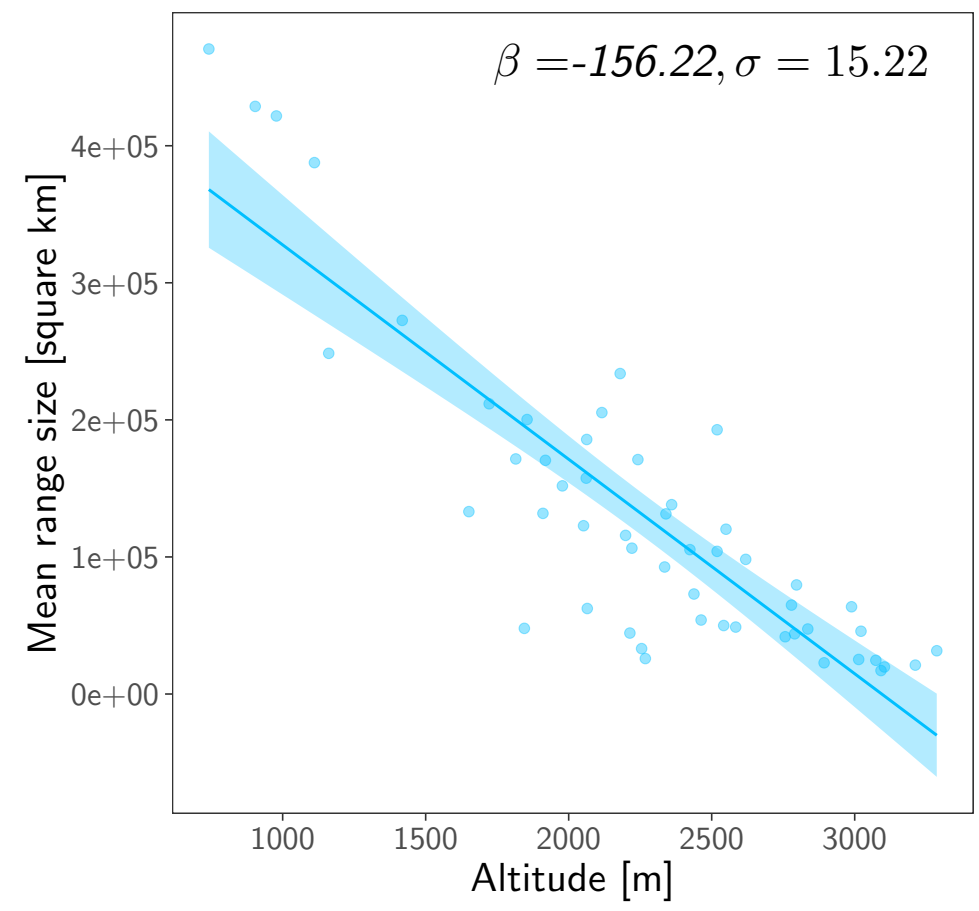

Fig. S5. Species from lower elevations tend to have larger range sizes. Relationship between species' mean range size and elevation. Range size is measured as area of occupancy (AOO; see Methods) and averaged across all species occurring at the baseline survey on a given mountain summit. Elevations of mountain summit sites ranged from 742 to $3,287 \mathrm{~m}$. Line and transparent ribbon present the mean regression line and $95 \%$ credible interval, $\beta$ is the slope, $\sigma$ is the standard deviation of $\beta$. 


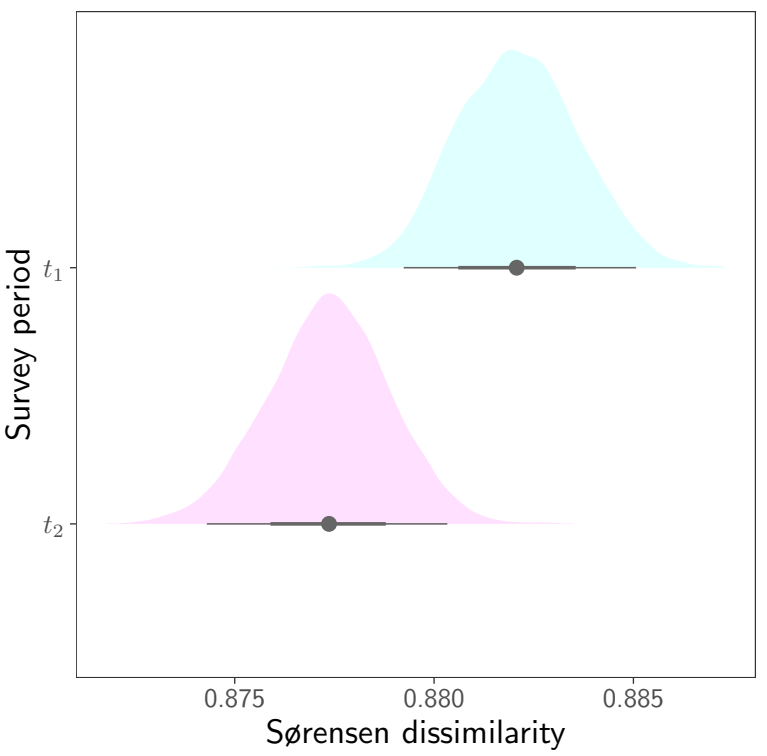

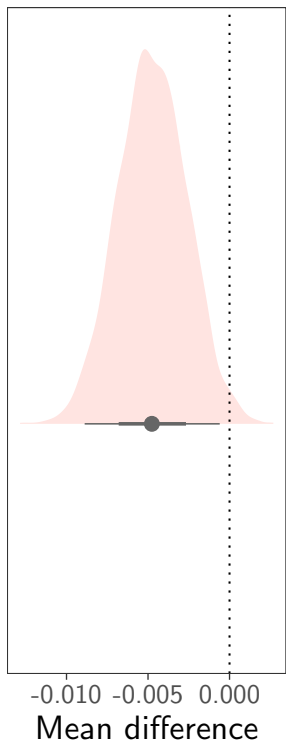

b Across habitats

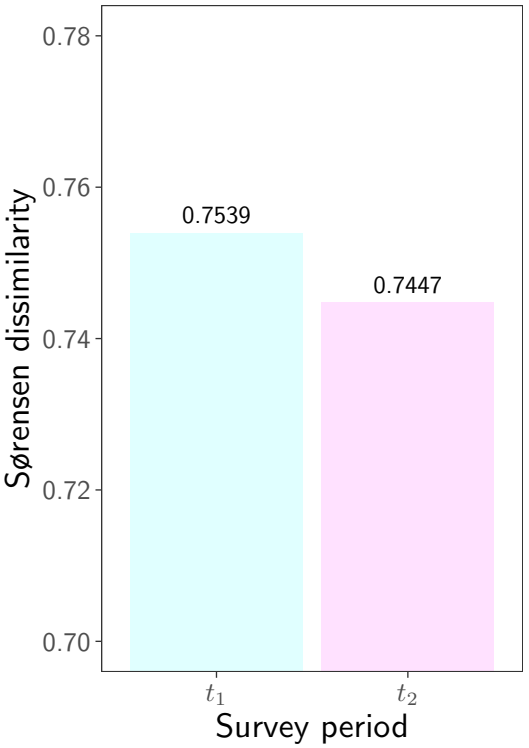

Fig. S6. Loss of beta-diversity over time. a, Posterior distribution of the mean beta-diversity of study sites at the baseline survey $\left(t_{1}\right)$ and resurvey $\left(t_{2}\right)$, calculated as Sørensen mean pair-wise dissimilarity between all possible pairs of the 141 sites in our study. b. Beta-diversity of the entire species pools of summits, forests and grasslands (calculated as Sørensen multiple-site dissimilarity between habitats) at the baseline survey $\left(t_{1}\right)$ and resurvey $\left(t_{2}\right)$. Point and lines in a are the median and its $66 \%$ and $95 \%$ credible interval. Dotted vertical line in a represents zero difference $\left(t_{2}-t_{1}\right)$ in beta-diversity. 

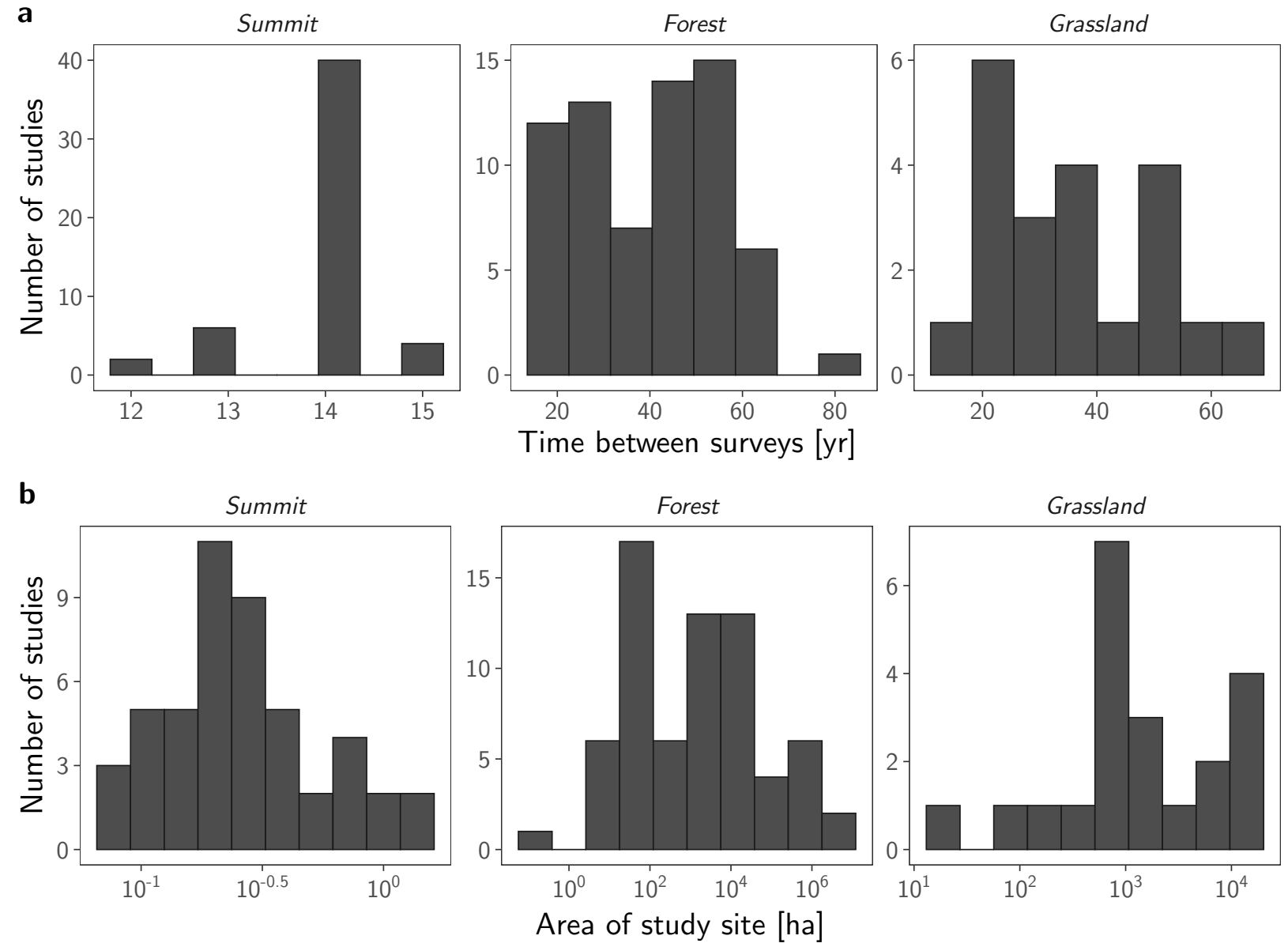

Fig. S7. Histogram of time span between surveys across study sites and site areas. a, Median time spans were 14, 42 and 34 years on mountain summits, forests and grasslands, respectively. b. Median site areas were $0.25,1,700$ and 1,000 ha on mountain summits, forests and grasslands, respectively. $\mathbf{X}$-axis in $\mathbf{b}$ is on the $\log 10$-scale. 
a

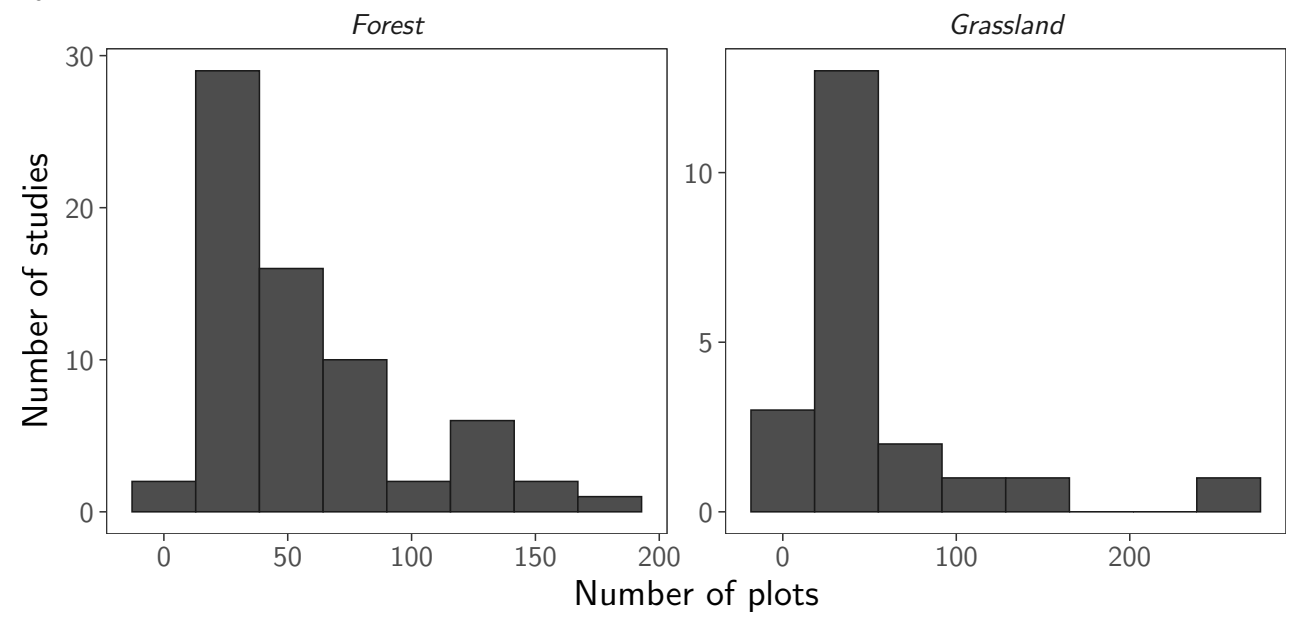

b
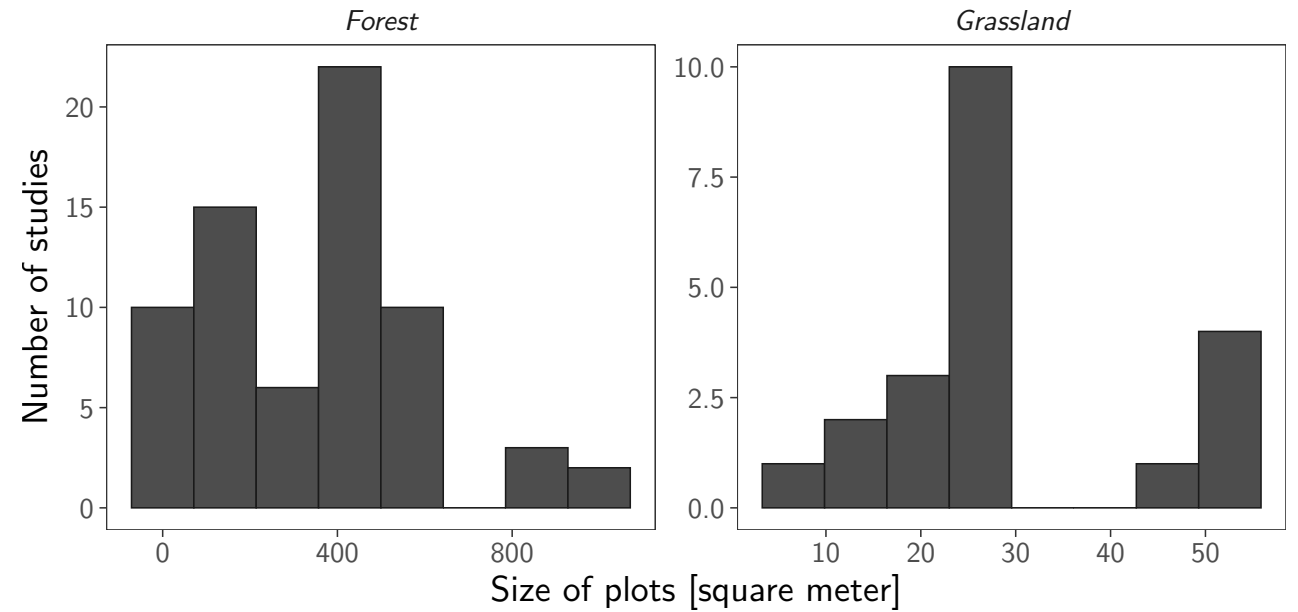

Fig. S8. Histogram of plot number and size. Forest and grasslands studies had a median of 43 and 36 plots with a size of $400 \mathrm{~m}^{2}$ and $25 \mathrm{~m}^{2}$, respectively. Studies on mountain summits were always divided into 8 sections that together covered the entire lateral area from the highest summit point to $10 \mathrm{~m}$ below this point. In total, our study counts 5,221 plots/sections. 

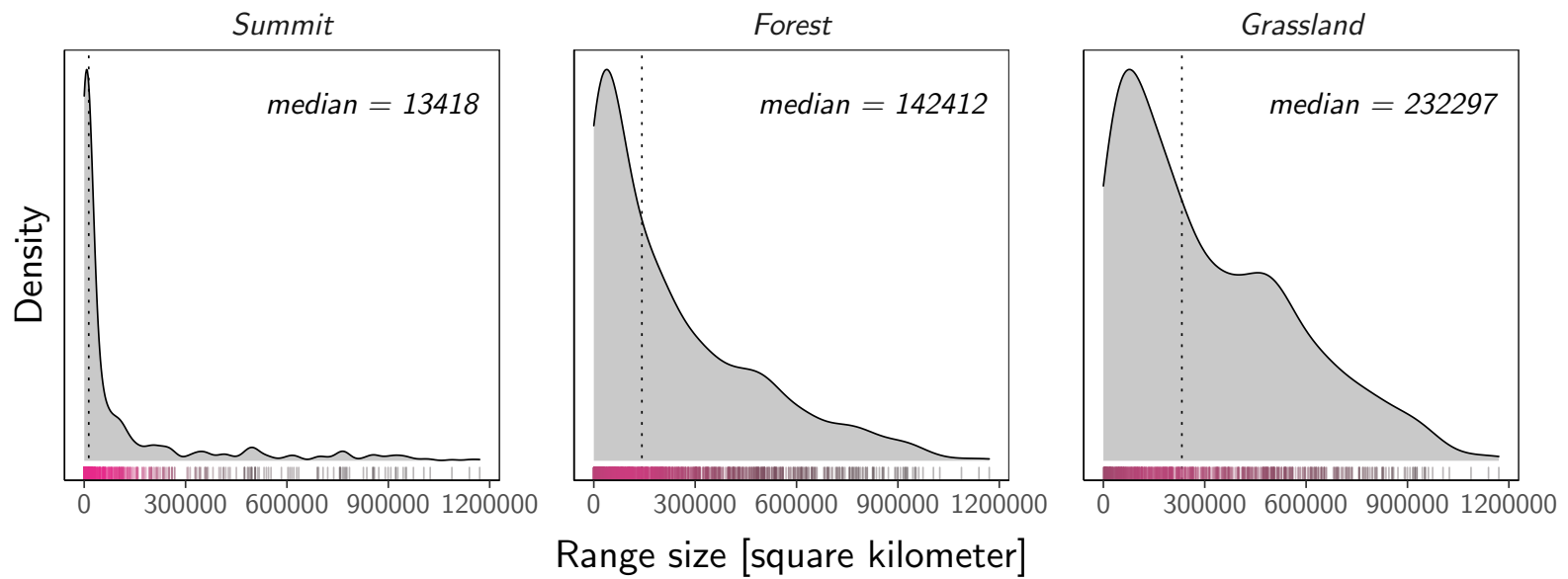

Fig. S9. Range size frequency distribution. Area of occupancy estimates of the species found in a given habitat (summit $=641$ species, forest $=1,148$ species, grassland $=692$ species). Dotted vertical line represents the median range size. Rug at the figure bottom represents the precise range sizes of species and is coloured to match the density of ticks. 

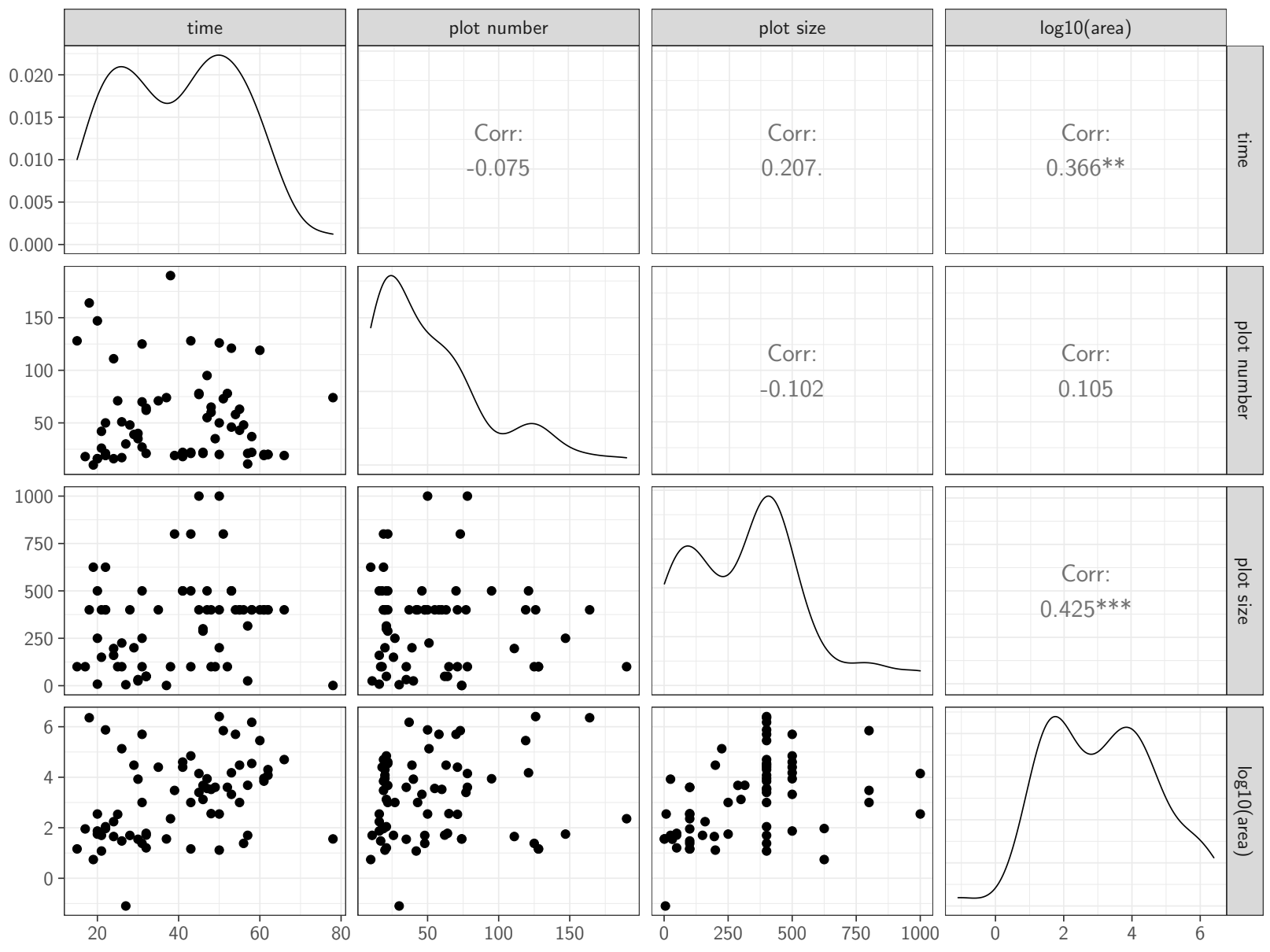

Fig. S10. Correlations between sampling characters of study sites in forests. Sampling characters are time interval between surveys, number of plots per site, size of plots and site area (log10-transformed). Since $\rho<0.7$ for all correlations, each character was included in the model testing whether the effect of range size depends on sampling method. 
Table S1. Country, site name, coordinates, year of the baseline survey and resurvey [when one survey (baseline or resurvey) was carried out over several years, the list shows the earliest baseline survey and the latest resurvey].

\begin{tabular}{|c|c|c|c|c|c|}
\hline Country & Site & Latitude & Longitude & Baseline (yr) & Resurvey (yr) \\
\hline \multicolumn{6}{|c|}{ Mountain summits } \\
\hline Austria & G'hacktkogel, NE-Alps / Hochschwab & 47.61 & 15.13 & 2001 & 2015 \\
\hline Austria & Weihbrunnkogel, NE-Alps / Hochschwab & 47.62 & 15.16 & 2001 & 2015 \\
\hline Austria & Zagelkogel-NW-summit, NE-Alps / Hochschwab & 47.61 & 15.12 & 2001 & 2015 \\
\hline Austria & Zinken-NW-summit, NE-Alps / Hochschwab & 47.60 & 15.09 & 2001 & 2015 \\
\hline Great Britain & Camp Cairn, Cairngorms & 57.09 & -3.84 & 2001 & 2015 \\
\hline Great Britain & Creag Mhigeachaidh, Cairngorms & 57.10 & -3.86 & 2001 & 2015 \\
\hline Great Britain & Sgoran Dubh Mor, Cairngorms & 57.08 & -3.81 & 2001 & 2015 \\
\hline Great Britain & Unknown Hillock, Cairngorms & 57.08 & -3.83 & 2001 & 2015 \\
\hline Italy & Alpe di Mommio, Northern Apennines & 44.28 & 10.24 & 2001 & 2015 \\
\hline Italy & Cima di Foce a Giovo, Northern Apennines & 44.12 & 10.61 & 2001 & 2015 \\
\hline Italy & Cima di Pian Cavallaro, Northern Apennines & 44.20 & 10.69 & 2001 & 2015 \\
\hline Italy & Cime Bianche, W-Alps / Mont Avic & 45.92 & 7.70 & 2002 & 2017 \\
\hline Italy & Colle Lago Bianco, W-Alps / Mont Avic & 45.65 & 7.60 & 2002 & 2017 \\
\hline Italy & Da Wöllane, Central Alps / Texelgruppe & 46.73 & 10.96 & 2003 & 2017 \\
\hline Italy & Do Peniola, S-Alps / Dolomites & 46.38 & 11.61 & 2001 & 2015 \\
\hline Italy & Faglmugl, Central Alps / Texelgruppe & 46.74 & 11.16 & 2003 & 2017 \\
\hline Italy & Grasmugl, S-Alps / Dolomites & 46.33 & 11.56 & 2001 & 2015 \\
\hline Italy & Kaserwartl, Central Alps / Texelgruppe & 46.76 & 10.88 & 2003 & 2017 \\
\hline Italy & Lago Balena, W-Alps / Mont Avic & 45.64 & 7.55 & 2002 & 2017 \\
\hline Italy & Monte Casarola, Northern Apennines & 44.33 & 10.21 & 2001 & 2015 \\
\hline Italy & Monte Schutto, S-Alps / Dolomites & 46.52 & 11.81 & 2001 & 2015 \\
\hline Italy & Pra Pelat, W-Alps / Mont Avic & 45.66 & 7.55 & 2002 & 2017 \\
\hline Italy & Ragnaroek, S-Alps / Dolomites & 46.38 & 11.59 & 2001 & 2015 \\
\hline Italy & Schafberg, Central Alps / Texelgruppe & 46.74 & 11.11 & 2003 & 2017 \\
\hline Norway & Kolla, S-Scandes / Dovrefjell & 62.29 & 9.49 & 2001 & 2015 \\
\hline Norway & Storkinn, S-Scandes / Dovrefjell & 62.35 & 9.44 & 2001 & 2015 \\
\hline Norway & Vesle Armodshokollen, S-Scandes / Dovrefjell & 62.26 & 9.67 & 2001 & 2015 \\
\hline Norway & Veslekolla, S-Scandes / Dovrefjell & 62.31 & 9.46 & 2001 & 2015 \\
\hline Romania & Buhaiescu, E-Carpathians / Rodnei Mts. & 47.58 & 24.63 & 2001 & 2015 \\
\hline Romania & Golgota, E-Carpathians / Rodnei Mts. & 47.60 & 24.63 & 2001 & 2015 \\
\hline Romania & Gropile, E-Carpathians / Rodnei Mts. & 47.57 & 24.62 & 2001 & 2015 \\
\hline Romania & Rebra, E-Carpathians / Rodnei Mts. & 47.59 & 24.64 & 2001 & 2015 \\
\hline Slovakia & Krátka, W-Carpathians / High Tatra & 49.16 & 20.01 & 2001 & 2015 \\
\hline
\end{tabular}




\begin{tabular}{|c|c|c|c|c|c|}
\hline Slovakia & Krížna, W-Carpathians / High Tatra & 49.18 & 19.95 & 2001 & 2015 \\
\hline Slovakia & Sedielková kopa, W-Carpathians / High Tatra & 49.15 & 20.02 & 2001 & 2015 \\
\hline Slovakia & Vel'ká kopa, W-Carpathians / High Tatra & 49.20 & 19.97 & 2001 & 2015 \\
\hline Spain & Punta Acuta, Central Pyrenees / Ordesa & 42.64 & -0.06 & 2001 & 2015 \\
\hline Spain & Punta Custodia, Central Pyrenees / Ordesa & 42.65 & 0.03 & 2001 & 2015 \\
\hline Spain & Punta de las Olas, Central Pyrenees / Ordesa & 42.66 & 0.05 & 2001 & 2015 \\
\hline Spain & Punta Tobacor, Central Pyrenees / Ordesa & 42.66 & -0.01 & 2001 & 2015 \\
\hline Switzerland & La Ly, W-Alpes / Alps of Valais-Entremont & 46.03 & 7.25 & 2001 & 2015 \\
\hline Switzerland & Minschuns, Central Alps / Swiss National Park & 46.65 & 10.34 & 2002 & 2015 \\
\hline Switzerland & Mont Brûlé, W-Alpes / Alps of Valais-Entremont & 46.02 & 7.20 & 2001 & 2015 \\
\hline Switzerland & Mot dal Gajer, Central Alps / Swiss National Park & 46.69 & 10.33 & 2002 & 2015 \\
\hline Switzerland & Mot sper Chamana Sesvenna, Central Alps / Swiss National Park & 46.74 & 10.43 & 2003 & 2015 \\
\hline Switzerland & Munt Buffalora, Central Alps / Swiss National Park & 46.64 & 10.24 & 2003 & 2015 \\
\hline Switzerland & Munt Chavagl, Central Alps / Swiss National Park & 46.64 & 10.23 & 2002 & 2015 \\
\hline Switzerland & Piz Foraz, Central Alps / Swiss National Park & 46.69 & 10.28 & 2002 & 2015 \\
\hline Switzerland & Piz Murtèr, Central Alps / Swiss National Park & 46.65 & 10.14 & 2002 & 2015 \\
\hline Switzerland & Piz Plazer, Central Alps / Swiss National Park & 46.71 & 10.39 & 2002 & 2015 \\
\hline Switzerland & Pointe de Boveire, W-Alpes / Alps of Valais-Entremont & 45.99 & 7.24 & 2001 & 2015 \\
\hline Switzerland & Pointe du Parc, W-Alpes / Alps of Valais-Entremont & 46.00 & 7.23 & 2001 & 2015 \\
\hline \multicolumn{6}{|c|}{ Deciduous and coniferous forests } \\
\hline Austria & Zöbelboden & 47.84 & 14.44 & 1993 & 2010 \\
\hline Belgium & Binnen-Vlaanderen & 51.09 & 3.54 & 1977 & 2009 \\
\hline Belgium & Florenne & 50.22 & 4.64 & 1957 & 2005 \\
\hline Belgium & Gaume & 49.62 & 5.56 & 1953 & 2008 \\
\hline Belgium & Herenbossen & 51.07 & 4.79 & 1980 & 2004 \\
\hline Belgium & Meerdaalwoud & 50.80 & 4.71 & 1954 & 2000 \\
\hline Belgium & Tournibus & 50.32 & 4.58 & 1967 & 2005 \\
\hline Belgium & Vorte Bossen & 51.07 & 3.37 & 1977 & 1998 \\
\hline Belgium & Zoerselbos & 51.25 & 4.68 & 1982 & 2008 \\
\hline Czech Republic & České Středohoří & 50.59 & 14.12 & 1965 & 2012 \\
\hline Czech Republic & Děvín Wood & 48.87 & 16.63 & 1953 & 2003 \\
\hline Czech Republic & Hodonínská Dúbrava & 48.88 & 17.10 & 1965 & 2012 \\
\hline Czech Republic & Krumlov Wood & 49.05 & 16.38 & 1964 & 2012 \\
\hline Czech Republic & Milíčovský les & 50.02 & 14.53 & 1986 & 2008 \\
\hline Czech Republic & Milovice Wood & 48.82 & 16.70 & 1953 & 2006 \\
\hline Czech Republic & Rychlebské hory Mts. & 50.27 & 17.08 & 1941 & 1999 \\
\hline Czech Republic & Ždánice Wood & 49.10 & 17.03 & 1959 & 2012 \\
\hline France & Andigny & 50.00 & 3.58 & 1957 & 1996 \\
\hline France & Compiègne forest & 49.36 & 2.89 & 1970 & 2015 \\
\hline
\end{tabular}




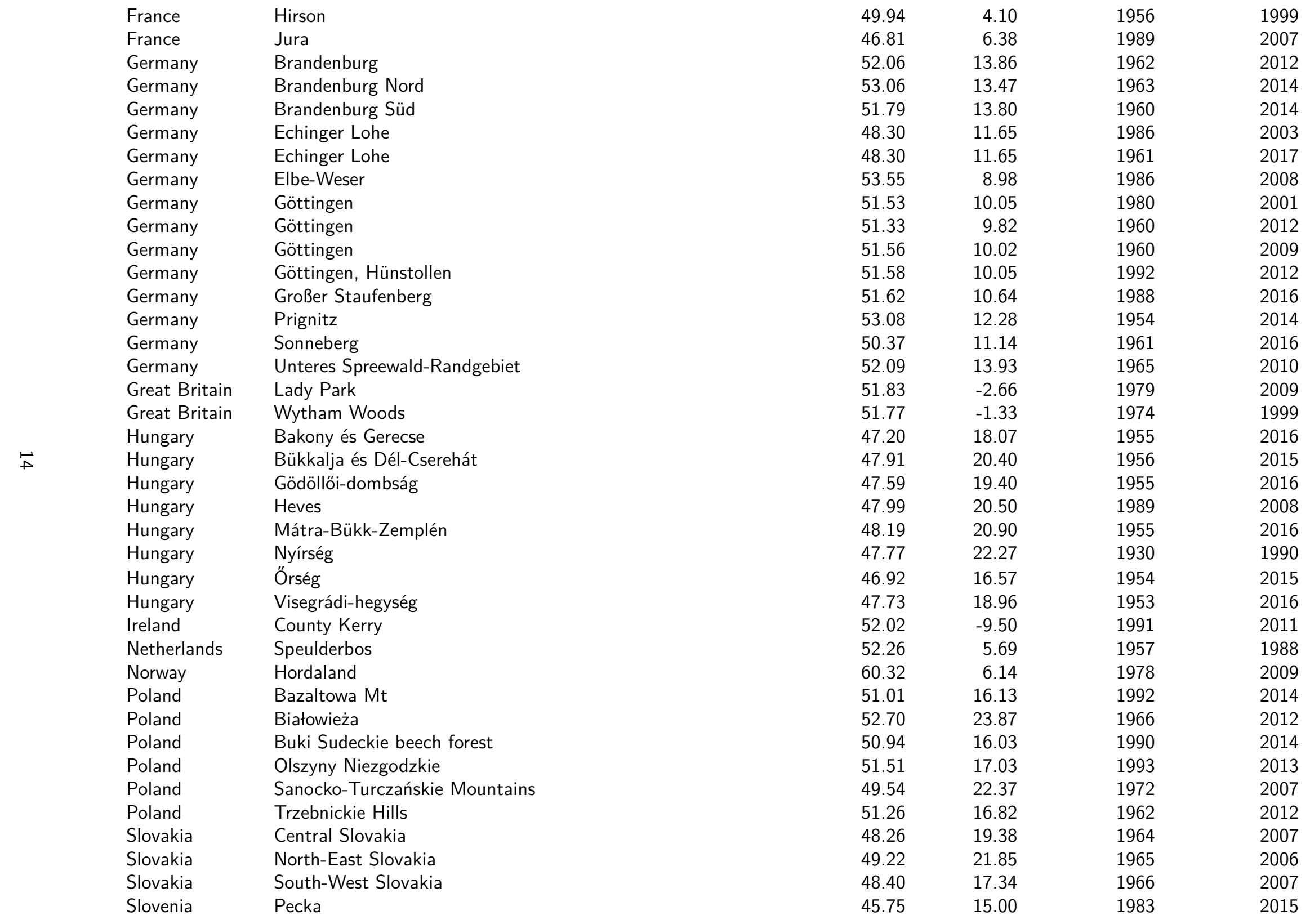




\begin{tabular}{|c|c|c|c|c|c|}
\hline Slovenia & Rajhenavski Rog & 45.66 & 15.01 & 1983 & 2015 \\
\hline Sweden & Dalby & 55.69 & 13.33 & 1935 & 2013 \\
\hline Sweden & Dalby & 55.69 & 13.33 & 1976 & 2013 \\
\hline Sweden & Öland & 56.67 & 16.53 & 1988 & 2014 \\
\hline Sweden & Stenshuvud & 55.66 & 14.26 & 1988 & 2015 \\
\hline Sweden & Tullgarn & 58.95 & 17.62 & 1971 & 2014 \\
\hline Sweden & Tullgarn & 58.95 & 17.62 & 1999 & 2014 \\
\hline Germany & Fränkischer Jura & 49.29 & 11.71 & 1931 & 1991 \\
\hline Germany & Fränkischer Jura & 49.29 & 11.71 & 1968 & 1991 \\
\hline Germany & Hessen & 50.81 & 8.89 & 1950 & 1990 \\
\hline Germany & Hessen & 50.78 & 8.93 & 1950 & 1990 \\
\hline Germany & Hessen & 50.82 & 8.90 & 1950 & 1990 \\
\hline Germany & Hessen & 51.23 & 9.92 & 1950 & 1991 \\
\hline Germany & Holtumer Moor & 53.00 & 9.30 & 1963 & 2006 \\
\hline Germany & Lange Damm Wiesen & 52.52 & 13.85 & 1991 & 2013 \\
\hline Germany & Ostetal & 53.32 & 9.24 & 1952 & 1987 \\
\hline Germany & Ostetal & 53.35 & 9.15 & 1964 & 1993 \\
\hline Germany & Stedinger Land & 53.14 & 8.56 & 1948 & 2015 \\
\hline Germany & Streeseebecken & 52.76 & 13.64 & 1992 & 2011 \\
\hline Great Britain & Dorset & 50.98 & -2.19 & 1952 & 2003 \\
\hline Great Britain & East Anglia & 52.04 & -0.04 & 1952 & 2003 \\
\hline Great Britain & Kent & 51.17 & 0.97 & 1952 & 2003 \\
\hline Great Britain & Yorkshire Wolds & 53.97 & -0.71 & 1952 & 2003 \\
\hline
\end{tabular}


Table S2. Summary of the model predicting species loss probability with species range size and baseline abundance (Fig. 3a). Model syntax, sampling settings, parameter estimates, their standard deviation (sd) and $95 \%$ credible interval (Cl). Rhat is the Gelman-Rubin convergence diagnostic, bulkand tail-ESS are the number of independent samples (i.e. effective sample sizes). Model includes species present at the baseline survey. Also, we ran the model excluding rare species (with a site-occupancy below $5 \%$ in the baseline survey) in forest and grassland to test for robustness of the range-size effect within these habitats.

Probability of species being lost at a study site

Formula: $\operatorname{logit}(p) \sim \operatorname{scale}(\log 10($ range $)) *$ scale $(\log 10($ occupancy $))+(1+\operatorname{scale}(\log 10($ occupancy $)) \mid$ site $)+(1 \mid$ speciesKey $)$

Number of observations: 2731 (summit), 7727 (forest), 2402 (grassland)

Number of group levels (species): 575 (summit), 989 (forest), 594 (grassland)

Number of group levels (study): 52 (summit), 68 (forest), 21 (grassland)

Sample settings: 4 chains, each with 2,000 iterations

\begin{tabular}{llrrrrrrr}
\hline Habitat & Parameter & Estimate & sd & I-95\% Cl & u-95\% Cl & Rhat & ESS bulk & ESS tail \\
\hline \multirow{2}{*}{ Summit } & Intercept & -3.44 & 0.28 & -4.03 & -2.94 & 1.00 & 1963 & 1916 \\
& Range size & -0.08 & 0.13 & -0.34 & 0.17 & 1.00 & 4250 & 3072 \\
& Occupancy & -1.63 & 0.17 & -2.00 & -1.32 & 1.00 & 2225 & 2168 \\
& Range size : occupancy & -0.02 & 0.09 & -0.20 & 0.17 & 1.00 & 4488 & 3163 \\
Forest & Intercept & -1.29 & 0.17 & -1.64 & -0.96 & 1.01 & 578 & 977 \\
& Range size & -0.18 & 0.04 & -0.27 & -0.10 & 1.00 & 4613 & 3426 \\
& Occupancy & -1.65 & 0.08 & -1.81 & -1.49 & 1.00 & 2916 & 3136 \\
& Range size : occupancy & 0.06 & 0.04 & -0.02 & 0.15 & 1.00 & 5990 & 3220 \\
Grassland & Intercept & -1.07 & 0.38 & -1.81 & -0.33 & 1.01 & 465 & 885 \\
& Range size & -0.40 & 0.10 & -0.59 & -0.20 & 1.00 & 2417 & 2796 \\
& Occupancy & -1.80 & 0.17 & -2.15 & -1.47 & 1.00 & 1064 & 2068 \\
& Range size : occupancy & -0.08 & 0.09 & -0.25 & 0.10 & 1.00 & 2769 & 2968 \\
\hline
\end{tabular}

Excluding rare species

Number of observations: 5407 (forest), 1684 (grassland)

Number of group levels (species): 834 (forest), 428 (grassland)

Number of group levels (study): 68 (forest), 21 (grassland)

Sample settings: 4 chains, each with 2,000 iterations

\begin{tabular}{llrrrrrrr}
\hline Habitat & Parameter & Estimate & sd & $\mathbf{I - 9 5 \% ~ C l}$ & u-95\% Cl & Rhat & ESS bulk & ESS tail \\
\hline Forest & Intercept & -2.35 & 0.20 & -2.76 & -1.97 & 1.00 & 691 & 1236 \\
& Range size & -0.16 & 0.06 & -0.28 & -0.04 & 1.00 & 3005 & 3290 \\
& Occupancy & -1.39 & 0.12 & -1.63 & -1.16 & 1.00 & 2115 & 2698 \\
& Range size : occupancy & 0.12 & 0.06 & 0.01 & 0.23 & 1.00 & 3844 & 3188 \\
Grassland & Intercept & -2.23 & 0.47 & -3.19 & -1.34 & 1.00 & 660 & 1296 \\
& Range size & -0.45 & 0.14 & -0.73 & -0.17 & 1.00 & 2795 & 3052 \\
& Occupancy & -1.49 & 0.16 & -1.84 & -1.19 & 1.00 & 1592 & 2359 \\
& Range size : occupancy & -0.16 & 0.12 & -0.39 & 0.08 & 1.00 & 2917 & 2888 \\
\hline
\end{tabular}


Table S3. Summaries of models for occupancy trends of persisting species in relation to range size (Supplementary Figure 3 and Fig. $3 b$ Model syntax, sampling settings, parameter estimates, their standard deviation (sd) and 95\% credible interval (CI). Rhat is the Gelman-Rubin convergence diagnostic, bulk- and tail-ESS are the number of independent samples (i.e. effective sample sizes). Models only includes persisting species. " $\Delta$ to decreasing" presents the posterior difference in estimated mean range size between increasing and decreasing species. Model on probability of increasing controls for species baseline occupancy, and excludes species with a baseline occupancy of 1 (see Methods).

Persisting increasing vs persisting decreasing: mean range sizes

Formula: $\log 10$ (range) $\sim$ occtrend $+(1 \mid$ study)

Number of observations: 2417 (summit), 5376 (forest), 1612 (grassland)

Number of group levels (study): 52 (summit), 68 (forest), 21 (grassland)

Sample settings: 4 chains, each with 2,000 iterations

\begin{tabular}{llrrrrrrr}
\hline Habitat & Parameter & Estimate & sd & I-95\% Cl & u-95\% Cl & Rhat & ESS bulk & ESS tail \\
\hline \multirow{2}{*}{ Summit } & Decreasing & 3.32 & 0.06 & 3.20 & 3.43 & 1.00 & 662 & 1407 \\
& Increasing ( $\Delta$ to decreasing) & 0.08 & 0.03 & 0.01 & 0.14 & 1.00 & 6139 & 3111 \\
Forest & Decreasing & 4.39 & 0.03 & 4.34 & 4.45 & 1.01 & 345 & 618 \\
& Increasing ( $\Delta$ to decreasing) & 0.10 & 0.01 & 0.07 & 0.13 & 1.00 & 4990 & 3247 \\
\multirow{2}{*}{ Grassland } & Decreasing & 4.57 & 0.05 & 4.46 & 4.66 & 1.01 & 519 & 747 \\
& Increasing ( $\Delta$ to decreasing) & 0.04 & 0.02 & 0.00 & 0.08 & 1.01 & 3407 & 2449 \\
\hline
\end{tabular}

Probability of persisting species increasing in occupancy

Formula: $\operatorname{logit}(p) \sim \operatorname{scale}(\log 10($ range $))+\operatorname{scale}(\log 10($ occupancy $))+(1+\operatorname{scale}(\log 10($ occupancy $)) \mid$ site $)+(1 \mid$ speciesKey $)$

Number of observations: 1909 (summit), 5250 (forest), 1600 (grassland)

Number of group levels (species): 511 (summit), 718 (forest), 451 (grassland)

Number of group levels (study): 52 (summit), 68 (forest), 21 (grassland)

Sample settings: 4 chains, each with 2,000 iterations

\begin{tabular}{llrrrrrrr}
\hline Habitat & Parameter & Estimate & sd & $\mathbf{l - 9 5 \% ~ C I}$ & u-95\% Cl & Rhat & ESS bulk & ESS tail \\
\hline Summit & Intercept & 0.09 & 0.12 & -0.15 & 0.34 & 1.00 & 1833 & 2139 \\
& Range size & 0.12 & 0.06 & 0.01 & 0.23 & 1.00 & 6277 & 3467 \\
& Occupancy & -0.05 & 0.06 & -0.16 & 0.07 & 1.00 & 4652 & 2900 \\
Forest & Intercept & -0.71 & 0.13 & -0.96 & -0.46 & 1.01 & 476 & 867 \\
& Range size & 0.26 & 0.05 & 0.15 & 0.36 & 1.00 & 1609 & 2275 \\
& Occupancy & -0.56 & 0.07 & -0.69 & -0.43 & 1.00 & 1395 & 2184 \\
\multirow{2}{*}{ Grassland } & Intercept & -0.62 & 0.21 & -1.03 & -0.21 & 1.00 & 750 & 1287 \\
& Range size & 0.20 & 0.08 & 0.05 & 0.35 & 1.00 & 3366 & 2931 \\
& Occupancy & -0.92 & 0.14 & -1.20 & -0.64 & 1.00 & 1630 & 2300 \\
\hline
\end{tabular}


Table S4. Summary of the model predicting species range size with species trajectory (Fig. $3 \mathbf{c}$ and d). Model syntax, sampling settings, parameter estimates, their standard deviation (sd) and $95 \%$ credible interval $(\mathrm{Cl})$. Rhat is the Gelman-Rubin convergence diagnostic, bulk- and tail-ESS are the number of independent samples (i.e. effective sample sizes). Model includes all 1,827 species in our database. " $\Delta$ to gained" presents the posterior difference in estimated mean range size between lost/persisting and gained species. Contrasts are calculated as differences between the posterior distribution of mean range sizes of trajectories (as opposed to Figure $3 c$ and $d$, model estimates are here in the log10-scale).

Gained vs lost (vs persisting): mean range sizes

Formula: $\log 10$ (range) $\sim$ trajectory $+(1 \mid$ study)

Number of observations: 3394 (summit), 9749 (forest), 3013 (grassland)

Number of group levels (study): 52 (summit), 68 (forest), 21 (grassland)

Sample settings: 4 chains, each with 2,000 iterations

\begin{tabular}{llrrrrrrr}
\hline Habitat & Parameter & Estimate & sd & I-95\% Cl & u-95\% CI & Rhat & ESS bulk & ESS tail \\
\hline Summit & Gained & 4.49 & 0.07 & 4.36 & 4.62 & 1.02 & 474 & 1093 \\
& Lost $(\Delta$ to gained) & -0.15 & 0.06 & -0.27 & -0.04 & 1.00 & 4469 & 3068 \\
& Persisted $(\Delta$ to gained) & -0.10 & 0.04 & -0.17 & -0.02 & 1.00 & 4070 & 2802 \\
Forest & Gained & 5.43 & 0.03 & 5.37 & 5.48 & 1.01 & 262 & 649 \\
& Lost $(\Delta$ to gained) & -0.11 & 0.02 & -0.15 & -0.08 & 1.00 & 2675 & 2703 \\
& Persisted $(\Delta$ to gained) & 0.04 & 0.01 & 0.01 & 0.07 & 1.00 & 2767 & 2767 \\
Grassland & Gained & 5.56 & 0.05 & 5.46 & 5.65 & 1.02 & 514 & 677 \\
& Lost $(\Delta$ to gained) & -0.11 & 0.02 & -0.15 & -0.07 & 1.00 & 2080 & 2547 \\
& Persisted $(\Delta$ to gained) & 0.05 & 0.02 & 0.01 & 0.09 & 1.00 & 2264 & 2474 \\
\hline
\end{tabular}

\begin{tabular}{llrrr} 
Contrasts & & & & \\
\hline Habitat & Parameter & Estimate & $\mathbf{I - 9 5 \% ~ C l}$ & $\mathbf{u - 9 5 \% ~ C l}$ \\
\hline \multirow{2}{*}{ Summit } & Gained - lost & 0.15 & 0.04 & 0.27 \\
& Persisted - lost & 0.06 & -0.04 & 0.16 \\
& Gained - persisted & 0.09 & 0.02 & 0.17 \\
Forest & Gained - lost & 0.12 & 0.08 & 0.15 \\
& Persisted - lost & 0.16 & 0.13 & 0.18 \\
& Gained - persisted & -0.04 & -0.07 & 0.00 \\
Grassland & Gained - lost & 0.11 & 0.07 & 0.15 \\
& Persisted - lost & 0.16 & 0.12 & 0.20 \\
& Gained - persisted & -0.05 & -0.09 & -0.01 \\
\hline
\end{tabular}


Table S5. Summary of the model testing for effects of sampling methods on the effect of range size on species loss probability. Model syntax, sampling settings, parameter estimates, their standard deviation (sd) and 95\% credible interval ( $\mathrm{Cl}$ ). Rhat is the Gelman-Rubin convergence diagnostic, bulk- and tail-ESS are the number of independent samples (i.e. effective sample sizes). Model is on forests, as forest study sites are most numerous and sampling characters (i.e. site areas, plot sizes/numbers and time intervals) varied here the most.

Interaction effect between range size and sampling methods

Formula:

$\operatorname{logit}(p) \sim \operatorname{scale}(\log 10($ range $)) *$ scale $(\log 10($ occupancy $))$

+ scale $(\log 10($ range $)) *$ scale $(\log 10($ area $))$

+ scale(log10(range)) * scale(plot size)

+ scale(log10(range)) * scale(plot number)

+ scale(log10(range)) * scale(time interval)

$+(1+$ scale $(\log 10($ occupancy $)) \mid$ site $)+(1 \mid$ speciesKey $)$

Number of observations: 7727

Number of group levels (species): 989

Number of group levels (study): 68

Sample settings: 4 chains, each with 2,000 iterations

\begin{tabular}{lrrrrrrr}
\hline Parameter & Estimate & sd & $\mathbf{I - 9 5 \% ~ C l}$ & $\mathbf{u - 9 5 \%} \mathbf{C l}$ & Rhat & ESS bulk & ESS tail \\
\hline Intercept & -1.46 & 0.14 & -1.75 & -1.18 & 1.01 & 946 & 1622 \\
Range size & -0.15 & 0.06 & -0.26 & -0.04 & 1.00 & 2716 & 3063 \\
Occupancy & -1.70 & 0.08 & -1.86 & -1.55 & 1.00 & 2023 & 2762 \\
Area & -0.26 & 0.13 & -0.53 & -0.01 & 1.01 & 897 & 1679 \\
Plot size & -0.06 & 0.12 & -0.30 & 0.18 & 1.00 & 1153 & 2023 \\
Plot number & -0.93 & 0.13 & -1.18 & -0.67 & 1.00 & 921 & 1366 \\
Time interval & 0.18 & 0.12 & -0.06 & 0.42 & 1.00 & 1064 & 1643 \\
Range size : occupancy & 0.06 & 0.05 & -0.04 & 0.16 & 1.00 & 3960 & 3049 \\
Range size : area & $\mathbf{- 0 . 0 5}$ & $\mathbf{0 . 0 6}$ & $\mathbf{- 0 . 1 6}$ & $\mathbf{0 . 0 6}$ & $\mathbf{1 . 0 0}$ & $\mathbf{3 4 3 3}$ & $\mathbf{3 3 9 2}$ \\
Range size : plot size & $\mathbf{0 . 0 0}$ & $\mathbf{0 . 0 4}$ & $\mathbf{- 0 . 0 9}$ & $\mathbf{0 . 0 8}$ & $\mathbf{1 . 0 0}$ & $\mathbf{7 2 2 2}$ & $\mathbf{3 0 9 6}$ \\
Range size : plot number & $\mathbf{0 . 0 0}$ & $\mathbf{0 . 0 5}$ & $\mathbf{- 0 . 1 0}$ & $\mathbf{0 . 1 0}$ & $\mathbf{1 . 0 0}$ & $\mathbf{4 4 3 6}$ & $\mathbf{3 0 0 0}$ \\
Range size : time interval & $\mathbf{- 0 . 0 7}$ & $\mathbf{0 . 0 5}$ & $\mathbf{- 0 . 1 6}$ & $\mathbf{0 . 0 3}$ & $\mathbf{1 . 0 0}$ & $\mathbf{3 8 0 1}$ & $\mathbf{2 9 9 7}$ \\
\hline
\end{tabular}

